\title{
A Review of Methodology for Accident Consequence Assessment
}
D. L. Strenge
J. K. Soldat
E. C. Watson

September 1978

Prepared for the

U.S. Nuclear Regulatory Commission

Pacific Northwest Laboratory

Operated for the U.S. Department of Energy by 


\title{
NOTICE
}

This report was prepared as an account of work sponsored by the United States Government. Neither the United States nor the United States Nuclear Regulatory Commission, nor any of their employees, nor any of their contractors, subcontractors, or their employees, makes any warranty, express or implied, or assumes any legal liability or responsibility for the accuracy, completeness or usefulness of any information, apparatus, product or process disclosed, or represents that its use would not infringe privately owned rights.

\author{
PACIFIC NORTHWEST LABORATORY \\ operated by \\ BATTELLE \\ for the
}

UNITED STATES DEPARTMENT OF ENERGY

Under Contract EY-76-C-06-1830
Printed in the United States of America Available from
National Technical Information Service
United States Departmen: of Commerce
5285 Por Royal Road
Springfield, Virginia 22151

Price: Printed Copy \$__; Microfiche $\$ 3.00$

NTIS

- Pages Seling Price

$007-025 \quad \$ 4.00$

$026-050 \quad \$ 4.50$

$051-075 \quad \$ 5.25$

$076-100 \quad 65.00$

$701-125 \quad \$ 6.50$

$126-150$ \$?. 25

$151-175 \quad \$ 8.00$

$176-200 \quad \$ 9.00$

$201-225 \quad \$ 9.25$

226-250 $\$ 9.50$

$251-275 \$ \$ 10.75$

$276-300 \quad \$ 11.00$ 
A REVIEW OF METHODOLOGY FOR ACCIDENT CONSEQUENCE ASSESSMENT

D. L. Strenge

J. K. Soldat

E. C. Watson

September 1978

Prepared for the

U.S. Nuclear Regulatory Commission

Pacific Northwest Laboratory

Richland, Washington 99352 



\section{PREFACE}

This report covers work performed under Phase I of a three-phase project. The desired end product of the project is a coherent set of mathematical models and computer codes which could be used to perform detailed environmental assessments for reactor accidents of classes 3 through 8 in a manner consistent with the methodology previously used in evaluating Class 9 reactor accidents and contained in the Reactor Safety Study (WASH-1400).

Modest modifications to the computer code used in WASH-1400 are suggested where these modifications accomplish one or more of the following at a minimum increase in complexity, computer running time and cost:

- Facilitate the use of site-specific meteorological, hydrological, demographic, land use, and economic data.

- Increase the compatibility between the methodology for evaluating the risks of Class 9 and Classes 3 through 8 reactor accidents.

- Increase the compatibility between the methodology for evaluating the risks of accident situations and that used for evaluating risks of routine (chronic) releases.

This project is part of a larger NRC program designed to facilitate a decision on whether to revise or re-issue as a Regulatory Guide a proposed Annex to 10 CFR 50 Appendix D.

It was originally sponsored by the Office of Standards Development (SD) whose personnel laid the ground work and shaped the initial efforts. Recently, the project was transferred to the Radiological Assessment Branch (RAB) of the Office of Nuclear Reactor Regulation (NRR) with a slight change in emphasis.

Dr. Sarbes Acharya, RAB, has provided valuable guidance as to the objectives of this study and its end-use within the larger NRC program. In addition, the authors benefited from the many worthwhile comments received during the intensive review of the initial draft of this report by $\mathrm{J}$. L. Mackin, SD, and others in the NRC. 


\section{ABSTRACT}

This report reviews current methodologies for reactor accident consequence analysis and describes areas where modifications are warranted.

Methodologies reviewed are:

- Models in Regulatory Guides $1.109,1.111$ and 1.113 used for evaluation of compliance with 10 CFR 50 Appendix I

- Models in Regulatory Guides used for evaluation of consequences from accidents of $\mathrm{Classes}$ 3-8

- Models for evaluation of Class 9 accidents presented in the Reactor Safety Study

- Models in the Liquid Pathway Generic Study.

The review is designed to aid in the ultimate goal of selection of a comprehensive set of models to extend the Class 9 methodology of the Reactor Safety Study to the analysis of Classes 3-8 accidents. 


\section{TABLE OF CONTENTS}

PREFACE ABSTRACT

1.0 INTRODUCTION

2.0 SOURCE TERMS . . . . . . . . . . . . . . . . . . .

2.1 SOURCE TERM FOR AIRBORNE PATHWAYS . . . . . . . .

2.2 SOURCE TERM FOR WATERBORNE PATHWAYS . . . . . . . .

2.3 SOURCE TERM FOR DIRECT IRRADIATION PATHWAY . . . . 2-2

3.0 ENVIRONMENTAL DISPERSION . . . . . . . . . . . . . .

3.1 DEFINITION OF ENVIRONMENT . . . . . . . . . . . . . .

3.2 ATMOSPHERIC DISPERSION . . . . . . . . . . . . . .

3.3 WATER DISPERSION . . . . . . . . . . . . . . 3-14

3.4 DiRECT IRRADIATION

4.0 EXPOSURE PATHWAYS . . . . . . . . . . . . . . . . . .

4.1 AIRBORNE PATHWAYS . . . . . . . . . . . . . . . . . .

4.2 WATERBORNE PATHWAYS . . . . . . . . . . . . . . 4 4-9

4.3 DIRECT DOSE . . . . . . . . . . . . . . . . . . . 4-12

5.0 DOSIMETRIC MODELS . . . . . . . . . . . . . . . . . . $5-1$

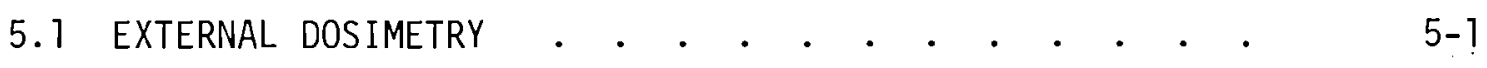

5.2 INTERNAL DOSIMETRY

6.0 HEALTH EFFECTS . . . . . . . . . . . . . . . . 6-1

6.1 EARLY SOMATIC EFFECTS . . . . . . . . . . . . 6-1

6.2 LATE SOMATIC EFFECTS . . . . . . . . . . . . .

6.3 GenetiC EFFECTS . . . . . . . . . . . . . . . $6-6$ 
7.0 EVACUATION AND SHELTERING . . . . . . . . . . . . . .

8.0 ECONOMIC COSTS . . . . . . . . . . . . . . . . . . .

8.1 EVACUATION COSTS . . . . . . . . . . . . . . . . .

8.2 INTERDICTION COSTS

8.3 DECONTAMINATION COSTS . . . . . . . . . . . . . . .

9.0 SUMMARY OF AREAS NEEDING FURTHER EFFORT . . . . . . . . . .

REFERENCES . . . . . . . . . . . . . . . . . Ref-1 


\subsection{INTRODUCTION}

The purpose of this report is to review current methodologies used for analysis of environmental consequences of releases of radionuclides in reactor accidents and to describe areas where further modeling development is desirable. The basis for the review consists of methodologies previously developed in four distinct types of effluent consequence analyses. These methodologies involve environmental assessment for:

- Compliance with 10 CFR 50 Appendix I as detailed in U.S. Nuclear Regulatory Commission Regulatory Guides 1.109, 1.111 and 1.113 (USNRC 1977a, b, c),

- Classes 3-8 accidents as detailed in U.S. Nuclear Regulatory Commission Regulatory Guides 1.3 (USAEC, 1974a), 1.4 (USAEC, 1974b), 1.5 (USAEC, 1971 ), 1.24 (USAEC, 1972a), 1.25 (USAEC, 1972b), 1.77 (USAEC, 1974c), 1.98 (USNRC, 1976a), and 4.2 (USNRC, 1976b).

- Class 9 accidents as detailed in the Reactor Safety Study, WASH-1400 (USNRC, 1975).

- Liquid Pathway Generic Study (USNRC, 1978).

The results of this study will be used as input to the USNRC decision making process concerning possible revision of a proposed Annex to 10 CFR 50 Appendix $D^{(a)}$ which provides some guidance for evaluation of environmental impacts from reactor accidents. It will also be used as a basis for extension of the current Class 9 methodology for application to Classes 3-8 assessments. The Reactor Safety Study provides a basis for analysis of consequences of reactor accidents of very low probabilities of occurrence and involving releases of relatively large quantities of radioactivity (Class 9 ) on a generic basis. The extension to Classes 3-8 accidents which are of higher probabilities but involve releases of lower quantities of radioactivity than Class 9 accidents, will involve consequence analysis on a site-specific basis. Also, several assumptions and simplifications were made in the Reactor Safety Study based on the Class 9 source terms. The broad range of releases

(a) The complete text of the proposed Annex to Appendix D, 10 CFR 50, is given in Appendix I to the Regulatory Guide 4.2 (USNRC, 1976b). The text was originally published in the Federal Register, December 1, 1971 (36 FR 2 2851). 
characterized by the accidents of Classes 3-8 will require re-evaluation of these assumptions and simplifications.

The methodology presented in the Regulatory Guides for evaluation of compliance with Appendix I is designed for routine effluent consequence analysis (except for transient aquatic models of Regulatory Guide 1.113). The models in these guides are therefore of limited use in accident consequence analysis. However, the models do provide a good representation of pathways and parameters which ought to be considered in the acute release situation.

The methodology presented in the Regulatory Guides for Classes 3-8 accidents is limited to evaluation of radiation dose (from air submersion and inhalation during cloud passage) at the site boundary and at the low population zone boundary. Regulatory Guides 1.3 and 1.4 for analys is of radiological consequences of loss-of-coolant accidents in boiling water reactors (BWRS) and pressurized water reactors (PWRS), respectively, provide comprehensive discussions of methods to use for almost all accidents of Classes 3-8 on the basis of conservative assumptions necessary for 1 icensing purposes. Other Regulatory Guides (RG) that present similar methods for analysis of radiological consequences include:

- RG 1.5 Main Steam Line Break Accident in BWRs

- RG 1.24 Radioactive Gas Storage Tank Failure in PWRs

- RG 1.25 Fuel Handling Accident in BWRs and PWRs

- RG 1.77 Control Rod Ejection Accident in PWRs

- RG 1.98 Radioactive Offgas System Failure in BWRs

Regulatory Guide 4.2 utilizes the methodologies of the preceding Regulatory Guides, although it adopts assumptions which are relatively less conservative. These models are discussed briefly in the following sections. For the most part, mathematical equations are omitted.

The review of current methodologies is biased by the ultimate goal of defining a comprehensive set of models to extend the class 9 methodology to the evaluation of Class 3-8 accidents. Even though selection of specific models is not an objective of this report, it is important to keep in mind 
the criteria to be used in the model selection. The primary goal in model selection is to develop a set of models capable of evaluating accident consequences. This goal can be realized by use of models that:

- include current state-of-the-art methods,

- describe phenomena as realistically as practicable,

- are responsive to site-specific data,

- are based on recommendations of experts,

- are mutually compatible, and

- can be programmed to run at reasonable cost.

The model review has been undertaken with these criteria in mind in order to make the report responsive to the ultimate task of model selection.

The starting point in the consequence calculation is the radionuclide inventory defined at some point in the reactor environment. The definition of the inventory depends on the exposure mode being considered. The three principal modes of interest are: airborne releases, waterborne releases and direct irradiation from activity contained within the reactor buildings. Models for each exposure mode are needed to describe transport of material and/or radiation to individuals and populations in the vicinity of the reactor. Dosimetry models are then used to convert exposure to radiation doses. The last step is to appiy a model to convert radiation dose to health effects and to estimate economic costs from contamination levels and dose levels. The discussions to follow are organized by this calculational scheme. 



\subsection{SOURCE TERMS}

The specification of the source term and associated parameters depends on the exposure mode being considered. The following three sections discuss requirements for each of the three exposure modes of interest to this study.

\subsection{SOURCE TERM FOR AIRBORNE PATHWAYS}

The three methodologies reviewed use similar models to represent the radionuclide source term. The activity of released material is defined for a given release period. For routine release analyses the annual release rate is specified. For acute releases the amount of material released in given time periods is defined. The methodology of Classes 3-8 accident analysis in Regulatory Guides 1.3 and 1.4 allows for up to five release periods ranging from about two hours up to thirty days. The Class 9 methodology of the Reactor Safety Study allows for only one release period of variable length up to 10 hours. Release times longer than 10 hours are not considered for Class 9 accidents. It should be noted that for accidents of classes 3-8 the release inventory is normally defined to match the release periods defined for the dispersion calculation. For this reason, discussion of release time periods is deferred to the section on dispersion.

Additional information on the physical characteristics of the release stream may be required. These include a definition of the stack height, stack diameter, exit velocity, heat content and dimensions of adjacent buildings. Such parameters are needed for the dispersion calculation, and their use will also be discussed in the section on atmospheric dispersion.

\subsection{SOURCE TERM FOR WATERBORNE PATHWAYS}

The source term for waterborne pathways is the quantity of radionuclides discharged from the facility's liquid effluent system, plus quantites released during other possible unplanned events which cause contamination to reach nearby surface waters. Additional information such as exit stream flow rate, discharge time, exit stream temperature and characteristics of the receiving waters are needed for the liquid dispersion calculation and will be discussed in that section. 
Of the four methodologies being reviewed, the only ones to consider 1 iquid effluents ${ }^{(a)}$ are the analysis described in Regulatory Guides 1.109 and 1.113 and the Liquid Pathway Generic Study (USNRC 1978). Both of these sources discuss models for entry and transport of radioactivity in aquatic environments. Models are presented for both acute and routine releases.

\subsection{SOURCE TERM FOR DIRECT IRRADIATION PATHWAY}

The direct irradiation pathway involves exposure of people near the reactor site from material contained within the plant structures. Under accident conditions it may be possible for activity to escape from the highly shielded reactor core to areas that provide lesser shielding, creating a potential exposure mode to persons near the plant. The source term required for this mode consists of the radionuclide inventory in selected portions of the plant along with data provided on the amount and type of structural shielding available. More than one such source term may be needed to model the potential locations of contamination within the buildings. The source term very likely will change with time not only because of radioactive decay, but also because of migration of radioactive materials into and out of various parts of the buildings.

(a) Work is currently being done at Sandia Laboratories on calculation of Class 9 accident consequences via liquid pathways. Review of Sandia models will be included in subsequent phases of this study. 


\subsection{ENVIRONMENTAL DISPERSION}

This section describes dispersion methodology for the three exposure modes. Airborne effluents are dispersed by the wind field present at the time of release. Waterborne effluents are dispersed by flow and/or dispersion mechanisms described for the particular type of receiving water body involved. For the direct irradiation exposure mode the "dispersion" is described by radiation transport through air and physical barriers. Before dispersion can be addressed in detail, it is necessary to describe certain aspects of the receptor environments such as location of individuals, calculational grid size and land usage. These parameters are site specific and must be evaluated for each site. After discussion of the environment, dispersion for each exposure mode will be discussed.

\subsection{DEFINITION OF ENVIRONMENT}

The location of certain important features of the surrounding environment must be defined with respect to the reactor. Important items to be defined are:

- demography

- surface water bodies,

- land usage,

- water usage,

- crop production (including agriculture, meat and milk products) and

- economic considerations.

Normally the population distribution is specified by defining a grid about the reactor site and giving the number of people within each segment as a function of distance and direction from the site. The methodology of the Reactor Safety Study and Regulatory Guide 1.109 divides the compass directions into 16 equal sectors of $22.5^{\circ}$ each. The radial mesh is defined by concentric circles about the site. 
The Reactor Safety Study covers a much larger distance from the site than does the Regulatory Guide. The radial distances used in the typical chronic release evaluations (Regulatory Guide 1.109 methodology) may provide sufficient definition of environmental parameters if supplemented by selected regional grid points to account for specific features that constitute a significant exposure pathway. The supplemental grid points may be randomly spaced to account for such features as cities or special crop production areas. Each grid point defined represents the effective center for the feature of concern with appropriate parameters defined for the area about the point.

The grid as defined above is of major importance in the airborne pathway analysis and to a lesser extent for the liquid pathways. For the direct irradiation mode, a finer grid may be desirable at close-in distances (<2 miles) since direct irradiation dose generally decreases rapidly with distance. Direction will also have to be specified for the direct irradiation pathway since the amount of shielding may vary with direction because of adjacent buildings and structures.

The environmental parameters required to define the waterborne pathways include location, size and flow of rivers, lakes, estuaries, impoundments and oceans. The location of groundwater aquifers may also be of interest, however, the groundwater pathway is not likely to be significant since reactors are generally located in areas where groundwater tends to flow toward the plant site, i.e., the potentially exposed population is located up gradient from the site. It is also necessary to define the location where people are exposed to the water or shoreline, and where drinking water supplies, irrigation water supplies and aquatic foodstuffs are obtained. All of the waterborne pathway environmental parameters must be defined on a site-specific basis.

\subsection{ATMOSPHERIC DISPERSION}

The discussion to follow is limited to the calculation of air concentrations at ground level and ground contamination concentrations at each grid point. The use of this data will be discussed under the dose pathway model 
section. The three methodologies reviewed that consider atmospheric dispersion are based on the Gaussian dispersion model.

The methodology in the Regulatory Guide 1.111 uses a straight line single point dispersion model with a cross wind averaged expression for dispersion within each sector as a function of distance. The Regulatory Guides 1.3 and 1.4 for evaluating dispersion for Class 3-8 accident use a bivariate straight line Gaussian expression for releases of 8 hours or less and a cross wind averaged expression for longer releases. The Reactor Safety Study uses a straight 1 ine model with the cross wind shape replaced by a rectangular form. Alt of these models assume the plume travels in a straight line.

The Reactor Safety Study model weights the results by the time (fraction of the year) the wind blows in each direction to partially account for wind direction variation. The Regulatory Guide 1.111 methodology uses joint frequency of occurrence data on wind speed, stability and wind direction to get annual average dispersion values as a function of distance and direction. None of these approaches fulty meet the requirement of determining dispersion as a function of distance and direction for an acute release on a site specific basis. The dispersion model is one area that should be updated in extending the Class 9 accident analysis to Class 3-8 accident analyses.

The model in the computer program CRAC (designed for Class 9 accidents in WASH-1400) determines downwind time integrated air concentrations in three steps. First, the sequence of hourly observations is used to assign average stability, precipitation index and wind speed values to each spatial interval. Next, the average values are used to calculate dispersion coefficients for each spatial interval in a sequential manner starting with the first interval and allowing the plume to grow in each interval according to the stability type for that interval. The third step is to use the dispersion parameters and plume rise data to calculate normalized time-integrated air concentrations (and ground concentration) for each spatial interval. The normalized time-integrated air concentrations are converted to nuclide activities using the release inventory and radioactive decay. Some of the assumptions inherent to this method are listed below. 
- The wind blows in the same direction until the material has passed beyond the last interval, normally 500 miles $(800 \mathrm{~km})$ in the CRAC grid. In the instance of forced precipitation the last interval is extended to 2,000 miles $(3,200 \mathrm{~km})$.

- Any distance interval that has precipitation in any portion is assumed to have precipitation over the entire interval.

- Spatial intervals spanned by more than one hour are represented by an averaged stability index and wind speed. It is important to note that parameters are being averaged rather than calculated air concentrations.

- Radioactive decay is determined for the average travel time to the interval being addressed.

- Calculations are based on parameters at the midpoint of each interval. The CRAC dispersion model is not suitable for use on a site-specific basis. A principal short-coming of the model is the lack of directional consideration of dispersion. Actual wind direction data should be included in the hourly observation data to provide actual dispersion pathways (directions) as a function of time. The straight-line averaged plume as used by CRAC does not properly account for these directional dependences.

Several types of atmospheric transport models have been developed to estimate the dispersion of material from a point source. These models range in complexity from simple straight line Gaussian dispersion models to particle-in-cell models. Characteristics of these models have been reviewed by Droppo (Strenge, et al, 1976) and Rosen (1977) and will not be discussed here. The more complex models have excessive input data and computer time requirements making them undesirable for the present application.

Desirable characteristics of the atmospheric model for the present application are as follows:

- The model must adequately describe transport near the site and at large distances (regional transport).

- The model must not have excessive data input requirements that could only be obtained at a few locations. 
- The mode1 must be programmable and not use excessive computational time.

- The model must have acceptable precision and accuracy.

A basic assumption in the consequence analysis is that the accident may occur at any time during the year. This means that transport from the release point may occur under a wide variety of atmospheric conditions. One method used to estimate probable transport from a given site is to base the dispersion calculation on hourly onsite meteorological observations (USNRC, 1975). In this method, referred to as the "window approach," the accident is allowed to start at each hour throughout the year (or at selected times). For a given starting day and time, the downwind dispersion is calculated as a function of distance and direction with the plume being followed until it leaves the area of consideration. For releases longer than one hour, additional hourly observations are used until the duration of release has been reached. The result of the calculation is a distribution of expected average air concentrations from each hour's release as a function of distance and direction from the release point. For releases lasting more than one hour, the concentrations are integrated to yield total exposure.

The Reactor Safety Study uses a window approach except that the plume is assumed to travel in a straight line and the duration of release is partially accounted for by an expansion factor. The air concentrations, plume width and resulting doses are calculated, based on a straight-line plume, from the hourly observations of wind speed and stability following a given start time. Directional variation is considered by applying annual windrose probabilities as weighting factors to the health effects and costs calculated for each sector. The short-coming of this approach is that the relationship between the data on actual wind vectors for a given trial (with specified start time) and the sectors likely to be affected during the release is not properly utilized by the use of the annual wind-rose probabilities as sector weighting factors.

When considering the dispersion on a site-specific basis, it is more precise to consider directional variation as a function of time rather than by use of annual average weighting factors. Use of hourly wind direction 
data would provide an indication of which sectors are likely to be covered by individual plumes. A method for including directional variations for a given accident start time is as follows: Air concentrations and resulting doses are again calculated on the basis of a straight-line plume (in the same manner as in the Reactor Safety Study). These straight line plume values are then applied to only those specific sectors that are likely to be affected as determined on the basis of the wind direction frequency for the sectors over the time period from the start of release until the plume leaves the final spatial interval. Health effects and costs are calculated for each sector affected and then weighted by this wind direction frequency for that sector. This method is consistent with the atmospheric dispersion methodology used with evaluation of chronic releases in Regulatory Guide 1.109 and is suggested for inclusion in the final computer program for all classes of reactor accidents.

Specific phenomena to be considered in the atmospheric transport model include plume rise, local terrain, building wake, dry deposition, and wet deposition. Models for most of these phenomena are presented in Regulatory Guides 1.109 and 1.111 and the Reactor Safety Study. Each item will be discussed separately in the sections below.

\subsubsection{Plume Rise}

This section compares models used for plume rise as presented in Regulatory Guide 1.111 and the Reactor Safety Study. Details of plume rise models in Regulatory Guide 1.111 are presented by Sagendorf (1974). Additional models are presented by Sagendorf and Goll (1977) as implemented in the NRC computer program XOQDOQ for calculation of atmospheric dispersion of routine effluents from nuclear power stations.

The appropriate model to use for plume rise depends on characteristics of the effluent plume. Ambient temperature releases from stacks are described by models for plume rise based on momentum of the exit stream. Routine effluent streams are usually described by momentum models such as those suggested in Regulatory Guide 1.111. Releases with significant heat content are affected by plume bouyancy. The Reactor Safety Study considers bouyancy to be dominant for effluents associated with Class 9 accidents. 
The methodology of Regulatory Guides 1.3 and 1.4 does not include specific models for plume rise. Regulatory Guide 1.5 arbitrarily assigns a release height of 30 meters to implicitly account for plume rise due to buoyancy and momentum associated with steam released in steam line break accidents in a boiling water reactor. Regulatory Guide 1.111 references momentum models of Briggs (1969) as presented by Sagendorf (1974). The Reactor Safety Study uses plume bouyancy models of Briggs (1969). Sagendorf and Go11 (1977) have included both momentum and bouyancy equations in the atmospheric dispersion program X0QD0Q. In addition to the plume rise models, Sagendorf and Goll suggest use of a mixed release mode model for vent releases where the release height is divided into elevated and ground components. This mixed mode representation was developed for routine release situations and may not be appropriate for acute releases.

Regulatory Guide 1.111 suggests use of a correction for downwash (Gifford, 1972) when the vertical exit velocity is less than 1.5 times the horizontal wind speed. The downwash correction is to be subracted from the effective plume height.

The plume rise model for accidents of Classes 3-8 should consider both momentum and bouyancy effects since a variety of effluent plumes may be encountered. Recent recommendations of Briggs (1975) should be included in the model.

\subsubsection{Building Wake Correction}

Material released from building vents, short stacks or at ground level may be subject to enhanced dispersion due to the turbulent wake caused by air flow around the building. Building wake corrections are generally considered only for ground level releases.

Regulatory Guides 1.3 and 1.4 suggest use of the building wake correction model presented by Slade (1968). This model is to be applied only to ground level releases of eight hours or less duration. The dispersion correction factor is 1 imited to the range of $1 / 3$ to 1 . The bivariate Gaussian dispersion equation for a normalized air concentration at ground level with building wake correction is: 


$$
\frac{\bar{x}}{\bar{Q}},=\frac{1}{\pi \Sigma_{y} \Sigma_{z} \bar{u}}
$$

where

$$
\begin{aligned}
& \bar{X} / Q^{\prime} \text { is the normalized air concentration }\left(\mathrm{sec} / \mathrm{m}^{3}\right) \\
& \bar{u} \text { is the windspeed at the elevation of release }(\mathrm{m} / \mathrm{sec}), \\
& \Sigma_{y}=\left(\sigma_{y}^{2}+0.5 \mathrm{~A} / \pi\right)^{\frac{1}{2}} \\
& \Sigma_{y}=\left(\sigma_{z}^{2}+0.5 \mathrm{~A} / \pi\right)^{\frac{1}{2}} \\
& \sigma_{y} \text { is the lateral dispersion coefficient }(\mathrm{m}), \\
& \sigma_{z} \text { is the vertical dispersion coefficient }(\mathrm{m}), \\
& A \text { is the minimum cross sectional area of the } \\
& \text { reactor building }\left(\mathrm{m}^{2}\right) \text {. }
\end{aligned}
$$

The Reactor Safety Study uses a similar approach to the building wake correction by adjusting the initial values of $\sigma_{y}$ and $\sigma_{z}$. The method is approximately equivalent to the following definition of $\Sigma_{y}$ and $\Sigma_{z}$.

$$
\begin{aligned}
& \Sigma_{y}=\sigma_{y}+B_{L} / 3 \\
& \Sigma_{z}=\sigma_{z}+B_{H} / 2.15
\end{aligned}
$$

where

$B_{L}$ is the building length perpendicular to the wind $(m)$, $\mathrm{B}_{H}$ is the building height $(m)$.

Regulatory Guide 1.111 presents a building wake correction model for the crosswind averaged Gaussian dispersion equation for ground level releases. In this model two expressions are used to evaluate downwind air concentrations with the larger value being used. The expressions as represented by Sagendorf (1974) for a ground level release are: 


$$
\frac{\bar{x}}{Q^{\prime}}=\frac{\sqrt{2 / \pi}}{r \theta \bar{u}} \cdot \frac{1}{\left(\sigma_{z}^{2}+0.5 D_{z}^{2} / \pi\right)^{\frac{1}{2}}}
$$

and

$$
\bar{Q}^{\prime}=\frac{\sqrt{2 / \bar{\pi}}}{r \theta \bar{u}} \quad \frac{1}{\sigma_{z} \sqrt{3}}
$$

where

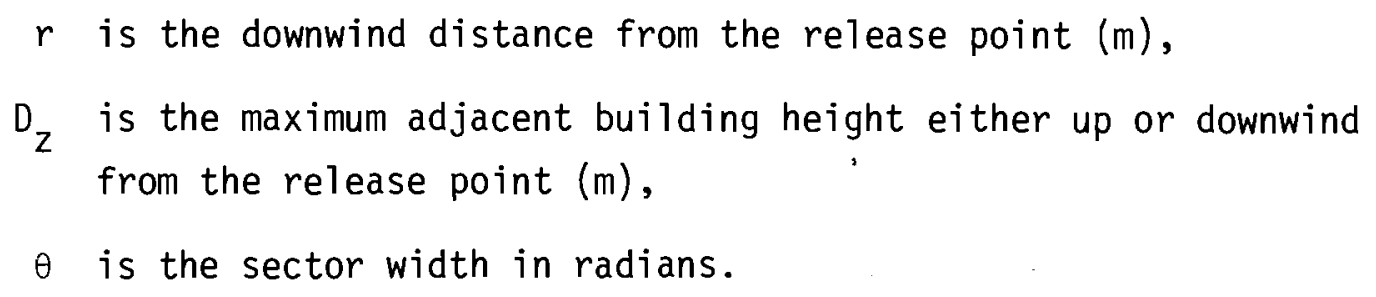

The building wake correction models described above are roughly equivalent.

\subsubsection{Local Terrain}

The only methodology to address effects of terrain variation is that of Regulatory Guide 1.111. The model presented in this guide suggests subtracting a terrain elevation value from the effective stack height after correction for plume rise. The value to subtract is taken as the maximum terrain height between the release point and the exposure point. The terrain height for purposes of this correction is the height above the stack base and must be greater than or equal to zero. This is known as the horizontal plume model for terrain correction. Another method is to assume that the plume follows the contour of the terrain (terrain conformal model) and hence the plume centerline is always a constant height above the ground.

As an alternative method Regulatory Guide 1.111 suggests the use of Egan's (1975) method for unstable and neutral conditions and Burt's method (Burt, 1977) for stable conditions. Egan's method assumes an intermediate trajectory halfway between the terrain conformal and horizontal plume models. 
Burt's method assumes the plume to be horizontal until the terrain rises to within 10 meters of the plume centerline. Then the plume is assumed to be terrain conformal at a distance of 10 meters above the terrain.

The model suggested in Regulatory Guide 1.111 is to be applied to straight line atmospheric dispersion models. This terrain model tends to produce conservative results (i.e., over estimate ground level air concentrations) which makes its application to the present study questionable. However; more complex models may not be practical to implement.

A more significant effect of local terrain variations on dispersion is the potential for directional flow variations. Such effects must be analyzed on a site-specific basis.

\subsubsection{Dry Deposition}

Dry deposition includes removal of particulates, vapors, and gases from plumes by the processes of settling, absorption on plants, and impaction. Dry deposition is considered in the methodologies of Regulatory Guide 1.111 and the Reactor Safety Study. Both sources assume radioiodines and particulates behave similarly with no removal of noble gases.

The Regulatory Guide 1.111 presents curves defining plume depletion and ground deposition for routine release situations. These curves define correction factors to be applied to plume concentrations at ground level to determine the depleted plume concentraton. Additional curves are presented to estimate ground deposition. All of these functional relationships are presented as a function of release height, atmospheric stability, and downwind distance. The figures are based on measurements of deposition velocity reported by Pelletier and Zimbrick (1970) and on a diffusion model as presented by Markee (1967).

The Reactor Safety Study uses a simple expression to describe the downward fluence of airborne contaminant.

$$
\text { Flux }=v_{d} x_{0}
$$


where

$$
\begin{aligned}
& v_{d} \text { is the deposition velocity }(\mathrm{m} / \mathrm{sec}), \\
& x_{0} \text { is the contaminant time integrated concentration at } \\
& \text { ground level }\left(\mathrm{Ci}-\mathrm{sec} / \mathrm{m}^{3}\right) .
\end{aligned}
$$

The deposition velocity is assumed to be constant. This is a simplifying assumption which ignores the many complex factors affecting deposition. Dry deposition is assumed to occur at all times. The value of the deposition velocity was taken as $10^{-2} \mathrm{~m} / \mathrm{sec}$ with a possible range suggested of $10^{-3}$ to $10^{-1} \mathrm{~m} / \mathrm{sec}$. These values were suggested for both particulates and gases except for noble gases which were assigned a value of $v_{d}=0$.

The calculation of plume depletion is made for each spatial interval where the fraction remaining airborne at the midpoint of the interval is given by:

$$
f=\exp \left(-v_{d} t_{j} / 2 \bar{z}\right)
$$

where

$f$ is the fraction of contaminant remaining airborne at the midpoint of the interval

$t_{i} / 2$ is the time of travel across half of the interval,

$\bar{z}$ is the effective plume thickness at the midpoint $(m)$.

The effective plume thickness is calculated as:

$$
\bar{z}=\left(\frac{\pi}{2}\right)^{1 / 2} \sigma_{z} \exp \left(h^{2} / 2 \sigma_{z}\right)^{2}
$$

The assumption is made the $\bar{z}$ is large and/or $t_{j}$ is small so that $f$ can be approximated by:

$$
f \simeq 1-v_{d} t_{i} / 2 z
$$


The factor $f$ is applied to the air concentration at the beginning of the interval to get the midpoint concentration. Then $f$ is applied again to the midpoint concentration to get the depletion to the end of the interval which is used for the calculations in the next interval. This is appropriate when $v_{d} t_{j} / 2 \bar{z}$ is small since $f^{2} \simeq 1-v_{d} t_{j} / \bar{z}$.

The ground contamination level is calculated in the Reactor Safety Study as:

where

$$
c_{g}=E_{m} \bar{z}\left(1-f^{2}\right) / t_{i}
$$

$\mathrm{C}_{\mathrm{g}}$ is the ground contamination for the spatial interval $\left(\mathrm{Ci} / \mathrm{m}^{2}\right)$,

$E_{m}$ is the depleted time-integrated air concentration at the midpoint of the interval $\left(\mathrm{Ci}-\mathrm{sec} / \mathrm{m}^{3}\right)$, and other terms are as previously defined.

The depletion and deposition calculations are performed for each nuclide with values of $v_{d}$ supplied for each nuclide through input. Even though a value of $10^{-2} \mathrm{~m} / \mathrm{sec}$ was suggested for $v_{d}$, other values could easily be used.

Possible improvements to the Reactor Safety Study deposition model would be:

- use of windspeed dependence of $v_{d}$ for iodine,

- use of different $v_{d}$ values for particulates,

- use of special $v_{d}$ values for elemental and organic iodine,

- use of improved cloud depletion model for stable conditions.

\subsubsection{Wet Deposition}

The many physical processes involved in wet deposition make this an area difficult to predict and model accurately. Methodologies suggested in Regulatory Guide 1.111 and the Reactor Safety Study rely on a simplified emperical approach. 
Regulatory Guide 1.111 suggests that wet deposition is not generally of significance for routine release situations because of the relatively small time the precipitation is likely to occur. If analysis shows that precipitation may be significant for a particular site, it is suggested that washout rates and plume concentration be calculated according to methods given by Engleman (1968). Engleman suggests using exponential expressions for the air concentration during periods of precipitation.

$$
x=x_{0} \exp (-\Omega t)
$$

where

$x$ is air concentration of contaminant at the location of interest $\left(\mathrm{Ci} / \mathrm{m}^{3}\right)$,

$x_{0}$ is air concentration at the start of precipitation $\left(\mathrm{C} i / \mathrm{m}^{3}\right)$,

$\Omega$ is the washout coefficient $\left(\mathrm{sec}^{-1}\right)$,

$t$ is the time since start of precipitation (sec).

This equation is for instantaneous concentration fields and must be integrated over time to determine time-integrated concentrations since time is used here as an independent variable.

The Reactor Safety Study uses the Engleman expression for washout with a washout coefficient $(\Omega)$, of $10^{-3}$ for unstable conditions and $10^{-4}$ for stable conditions. This model was used for particulates and gases except that noble gases are not depleted by precipitation. The fraction of material removed is calculated as;

$$
f=1-x / x_{0}
$$

This material was uniformly distributed over the spatial interval in which it was deposited.

In applying this model the Reactor Safety Study computer code first determines the duration of precipitation for a given spatial interval from 
hourly observation data. An average rain duration of one half of this time was then used in the wet deposition calculation.

A possible improvement to the rain depletion model would be to use actual precipitation rate data to determine the effective deposition velocity. This would eliminate the need to assume a rain duration. Such a model could be expressed as:

$$
\Omega=\Omega_{1} P
$$

where

$$
\begin{aligned}
& \Omega_{1} \text { is the washout coefficient }\left(\mathrm{sec}^{-1} \mathrm{per} \mathrm{mm} / \mathrm{hr}\right) \text { corresponding to } \\
& \text { a precipitation rate of } 1 \mathrm{~mm} / \mathrm{hr}, \\
& P \text { is the observed precipitation rate }(\mathrm{mm} / \mathrm{hr}) .
\end{aligned}
$$

Equation 15 represents a 1 inear relation, however, a non-1inear model may be more suitable.

\subsection{WATER DISPERSION}

Releases of contamination via aqueous waste streams may result in contamination of nearby water bodies. The purpose of this section is to describe models to relate transport from the release point to the selected points of interest in the environment. The result of the calculation is the water concentration at the selected points.

In performing the transport analysis it is first necessary to estimate the initial dilution from the effluent jet or diffuser. The initial dilution is used as the starting point for the transport model for the particular water body type under consideration.

As mentioned previously, models for the waterborne pathway are given in Regulatory Guides 1.109 (USNRC, 1977a) and 1.113 (USNRC, 1977c) and the Liquid Pathway Generic Study (USNRC, 1978). Models presented range from simple closed-form analytic solutions to complex models requiring a numerical solution. Models are discussed in Regulatory Guide 1.113 for non-tidal rivers, open coasts, estuaries and impoundments. The model to be used for a particular 
application should be determined from consideration of site specific requirements and the availability of parameters and data. Tracer studies performed to determine dispersion for the site of interest may be used instead of a mode1.

The sections which follow provide a summary discussion of the models presented in the reference documents. These models provide a basis for aquatic dispersion sufficient for accidents of classes 3-9.

\subsubsection{Initial Dilution}

The effluent stream is generally discharged to the receiving water through high-velocity jet or multiport diffuser to enhance the dilution. Detailed discussions of the resulting near-field dilution models are given by Jirka, Abraham and Harleman (1976) and Dunn, Policastro and Paddock (1975). These references give guidance on model selection for specific applications. The models may be categorized into surface discharge models and submerged discharge models.

Surface discharge dilution is dependent on shoreline and bottom interference. References describing these models include Stolzenbach and Harleman (1971), Stolzenbach, et a1. (1972), Prych (1972), Shirazi and Davis (1974) and Pritchard (1971 and 1973).

Initial dilution models for submerged jets depend on the flow conditions of the receiving water body. Release from deep-water sources are characterized as stable discharges wherein the discharged effluent forms a stable density current with little re-entrainment of previously discharged effluent. Shallow-water releases are characterized as unstable wherein counterflow causes re-entrainment of previously discharged water. Models for deep-water releases are given by Koh and Fan (1970) and Hirst (1971). Shallow water release initial dilution may be estimated by models of Lee, et al. (1974) and Jirka and Harleman (1973).

For site specific applications measurements of mixing and dilution may be available from pre-operational or post-operational release studies. Temp- 
erature measurements made for evaluation of thermal effects can be used to estimate radionuclide dilution if proper account is taken for heat loss due to evaporation.

\subsubsection{Non-Tidal Rivers}

Effluent transport from reactors located on non-tidal rivers can be estimated using the transient release model of Regulatory Guide 1.113. This model represents a vertical line source in a straight rectangular channel. Parameters required for this model are the lateral and longitudinal turbulent diffusion coefficient, stream channel geometry and a definition of stream discharge. The model predicts concentration as a function of time at a selected downstream location. A steady-state stream tube model is also presented which could be useful for prolonged releases. This model assumes the river flow to be uniform and steady. Irregular channel geometries may be considered.

The Liauid Pathway Generic Study (LPGS) presents a steady-state model for core-melt accidents based on the Clinch-Tennessee-Ohio-Mississippi River system. The Clinch River is represented by a plug flow model while the Tennessee River is represented by a series of perfectly mixed reservoirs. since it is extensively dammed. An important feature of this model is the sorption of radioactivity by suspended and bottom sediments. The reservoir model considers scavenging by falling sediment and direct transfer from water to bottom sediments. The Ohio and Mississippi River models account only for dilution since sedimentation is less important in free running waters. A steady-state model is used for this river system since it is assumed that release from a core-melt accident would be via the ground water pathway. Parameters required for the reservoir model are flow rate, volume, average depth of water layer, average depth of sediment layer and the sedimentation rate. These parameters must be supplied for each reservoir in the system. The plug flow model (used for the $\mathrm{Clinch}$ River) requires the same information plus the average velocity in the channel. 


\subsubsection{Coastal Waters}

Models for dispersion in coastal water are discussed in Regulatory Guide 1.113 for the two types of shorelines of interest in the U.S.; Great Lakes and ocean coasts.

Transient and steady state models which prescribe dispersion along shoreline sites on the Great Lakes are presented. The models are valid for distances of about $25 \mathrm{~km}$ and for times on the order of a few days. The transient source model which is of interest for accidental releases, requires as input the lateral and longitudinal diffusion coefficients, the longshore current, the location of the exposure point with respect to the release and the time after release. Perhaps a few specific sites can be found where al1 of the parameters have been measured or estimated.

The LPGS describes models for dispersion in Great Lakes to cover nearshore, offshore and totally mixed regimes. The near-shore model is the same as the Regulatory Guide 1.113 model just described. The offshore model for instantaneous release describes dispersion after the pollutant has left the shoreline zone and before it is totally mixed. The offshore model is represented by a radially symmetric Gaussian diffusing patch wherein the pollutant is assumed not to penetrate the thermocline. Parameters required for this model are the depth of the thermocline and the area of the patch defined as a function of time after release. An expression is presented for the area time dependence for Lake Ontario.

Two models are presented in the LPGS for totally mixed regimes: a shortterm model for design basis accidents and a long-term model for core-melt accidents. The first model describes transient behavior in a series of perfectly mixed test tanks (lakes) without sediment transport considerations. Parameters needed for this model include lake volume and inflow and outflow rates. The long-term dispersion is represented by a two-compartment model; sediment and water. Transfer phenomena considered by this model include:

- lake inflow rate

- flushing of dissolved material from the lake (outflow),

- sediment deposition on the lake bottom, 
- direct exchange from water to sediment,

- direct exchange from sediment to water,

- removal of bottom sediment layer by burial,

- radioactive decay.

Parameters required for this model are fresh water flow rate, lake volume, sediment deposition rate, pollutant equilibrium distribution coefficient, average depth of lake and the coefficient for direct transfer to the sediment.

A discussion of models for ocean shore transport is given with references for various numerical models. Models of ocean coastal waters are similar to Great Lakes models with the primary difference lying in the greater temporal and spatial variability in ocean coastal systems. Two factors important for ocean models are tidal currents (small in the Great Lakes) and meteorological driving forces.

\subsubsection{Estuaries}

Dispersion of contaminants in estuaries is characterized by oscillatory tidal advection and non-tidal gravitational circulation due to salinity density differences. As a result of these mechanisms there is a potential for upstream transport of contaminants. Regulatory Guide 1.113 presents analytical models for both short duration and steady-state releases to estuaries. These are one-dimensional models requiring as input the longitudinal dispersion coefficient, the average fresh-water velocity, the radiological decay constant, average cross-sectional area of flow and distance from the release point (either upstream or downstream).

The LPGS suggests use of the model described in Regulatory Guide 1.113 for design basis accidents. For core-melt accidents the model is modified to account for sedimentation effects. The distribution of radionuclides between the water and sediment phases is based on chemical equilibrium with concentration related by the equilibrium distribution coefficient. Parameters required for this model in addition to those mentioned above are equilibrium distribution coefficient, water layer thickness, sediment layer thickness and the net downstream velocity of the sediment bed. 
More complex numerical models are discussed in the LPGS to simulate transport under special circumstances, such as in estuaries with non-uniform cross-sections, tidal coordinated releases and very wide estuaries. The parameter values required for these more complex models will seldom all be available for a specific site.

\subsubsection{Cooling Ponds}

There are two general types of cooling ponds to be considered: Closedloop systems and flow-through systems. In closed-loop systems the thermal effluent is cooled in the pond and reused as input to the power plant condensers. The flow-through system involves discharge of thermal effluent to a holding pond which discharges to the receiving water body without reuse.

Regulatory Guide 1.113 presents transient and steady-state models for both types of cooling ponds. The closed-loop system is represented by a model which assumes complete mixing in the cooling pond. The flow-through system is represented by a plug flow model. A third model is presented which is a combination of the completely mixed model and the plug flow model to be used for the closed-1oop system when a significant amount of plant input is from fresh make-up. Data required for these models includes flow rates for plant intake, fresh make-up and pond discharge and pond volume.

A stratified reservoir model (Trent, 1975) is also presented for large cooling reservoirs that have seasonal turnover. Two periods are defined; a stratified period where the two layers are each totally mixed and an unstratified period where the entire pond contents are totally mixed. Data required for this model include the duration of each period, the volume in each layer, the inflow and withdrawal rates and the inflow contamination level.

These models are mathematically simple, but they represent complex coolingpond dynamics well enough for the needs of this study if care is taken in defining the input parameters. 


\subsection{DIRECT IRRADIATION}

The direct exposure pathway involves radiation transport through structural materials and air. The principal radiation of interest is gamma radiation. Other radiations do not have significant ranges to irradiate individuals outside of the nuclear facility. A possible exception would be neutron radiation from a criticality in fuel outside the reactor core.

None of the methodologies reviewed considered direct irradiation to be a significant exposure mode. Models and computer programs are available for estimating gamma radiation transport from a variety of geometric shapes and shielding configurations. One such compilation of models is provided in the computer program ISOSHLD (Engle, et. al., 1966). ISOSHLD employs a point kernel numerical integration method for several simple geometries with shielding. There are several other computer programs that have been shown to be consistent with each other, in the domains of their validity, by the ANS Working Group 6.6 (1977) using a set of simple benchmark problems. Calculational methods used in these programs include Monte Carlo, descrete ordinates, point kernel and numerical integration of parametric air-scattering data.

Simple radiation shielding and transport models (such as those in ISOSHLD) should suffice for the needs of this project. 


\subsection{EXPOSURE PATHWAYS}

The previous section discussed models for estimating concentrations of radionuclides in environmental media at selected points in the environment. This section reviews models for determining radiation doses to individuals resulting from the calculated environmental contamination levels. The pathways are discussed for each of 3 exposure modes: airborne, waterborne and direct exposure from contained radionuclides.

The calculation of dose can be accomplished by utilizing dose conversion factors relating intake of radionuclides to dose. Dose factor compilations are given in Regulatory Guide 1.109, NUREG-0172 (Hoenes and Soldat, 1977) and the Reactor Safety Study. Models for internal and external dosimetry are covered in Section 5.0 .

\subsection{AIRBORNE PATHWAYS}

Five airborne pathways have been identified for inclusion in this study:

- External dose from the passing cloud

- Internal dose from radionuclides inhaled during cloud passage

- External dose from material deposited on the ground

- Internal dose from ingestion of farm products contaminated by deposition

- Internal dose from inhalation of resuspended radionuclides.

Each of these pathways is discussed separately in the following sections.

\subsubsection{External Dose from Cloud}

Persons near the contaminated plume may be exposed from both gamma and beta radiations. While beta radiation exposure is limited to persons within a few meters of the contaminated air, gamma radiation exposure can occur at much larger distances from the cloud.

Contributions to dose from beta radiations may be calculated directly from radionuclide air concentrations using a $2 \pi$ geometry. Due to their short range in tissue, beta particles normally only irradiate the skin.

Calculation of the gamma contribution to dose requires consideration of the spatial distribution of contamination within the plume. When the 
plume dimensions are large compared to the mean free path of the gamma radiations in air and the plume is near or at the ground, the plume may be assumed to have a uniform concentration and to be of semi-infinite dimensions (bounded by the ground plane). Under this assumption the gamma radiation dose is proportional to the average radionuclide air concentration. When the plume dimensions are of the order of the mean free path of gamma radiation or smaller, it is necessary to consider the finite dimension of the plume. In this case the radiation dose must be calculated by integration over the active portion of the plume. This requires a knowledge of the plume size at the exposure location. External gamma radiation, i.e., radiation from sources external to the body, can lead to exposure of all organs of the body.

A11 three methodologies evaluated here consider the external exposure pathway. The external exposure model of Regulatory Guides 1.3 and 1.4 is based on the semi-infinite plume approach. Regulatory Guide 1.109 suggests use of the finite plume approach when calculating external exposure from noble gases released from free-standing stacks over 80 meters high. For releases at lower elevations the semi-infinite model is used. Regulatory Guide 1.109 considers only noble gases when calculating external exposure from cloud passage. The Reactor Safety Study model calculates external exposure by the semi-infinite plume model and then uses a table of correction factors to account for effects of plume size. The correction factors are tabulated as a function of plume centerline height and vertical dispersion and are applied equally to all nuclides. Both the Regulatory Guide 1.109 model for chronic release and the Reactor Safety Study model for acute release are based on models described by Slade (1968).

The Reactor Safety Study model could be improved by expanding the correction factor table to include dependence on gamma energy and lateral dispersion.

\subsubsection{Inhalation During Cloud Passage}

Persons in the path of the contaminated plume will be subject to radiation doses to internal organs through the inhalation pathway. The resulting dose is dependent on air concentration, breathing rate, exposure times, and physical properties of the contaminant. The critical portion of the inhalation pathway calculation is the determination of intake. Once intake has 
been determined, dose may easily be calculated using appropriate dose conversion factors. (This is true of ingestion pathways also.) All three methodologies treat inhalation differently. The differences in the methods lie in the determination of air concentration (Section 3 ) and the lung dosimetry model used (Section 5).

Regulatory Guides 1.3 and 1.4 consider the inhalation pathway for radioiodines only. Regulatory Guide 1.109 and the Reactor Safety Study consider the inhalation of all important radionuclides. The Reactor Safety Study is the only one of the three methodologies to consider inhalation of resuspended material (see Section 4.1.5).

\subsubsection{External Dose from Ground Contamination}

The atmospheric dispersion calculation provides the concentrations of radioisotopes on the ground. Persons in the vicinity of the contaminated ground are subject to radiation exposure principally from gamma radiation. The actual dose received is dependent on several parameters that are often difficult to define.

The degree to which the contamination is retained on plant and soil surfaces with time (weathering) affects the resulting exposure. The Reactor Safety Study uses a double exponential expression. for weathering given by

$$
f_{W}(t)=0.63 \exp (-0.693 t / 0.612)+0.37 \exp (-0.693 t / 92.6)
$$

where

$$
\begin{aligned}
& f_{w}(t) \text { is the fraction of initial deposition available to contribute } \\
& \text { to external dose at time } t \text {, (years). }
\end{aligned}
$$

The model of Regulatory Guide 1.109 for routine releases uses no reduction due to weathering. When acute releases are considered, some estimate should be made of weathering effects since experimental evidence indicates that radionuclides generally migrate downward into the soil, especially during periods of rain or irrigation. 
Another factor reducing external dose is the shielding afforded by structures. Burson and Profio (1975) have summarized shielding factors for several activities and for various structures. The effective shielding factor for any population depends on average occupancy times for buildings and activities in the vicinity of the contamination. The Reactor Safety Study suggests a shielding factor of 0.33 when there is no evacuation and a factor of 0.5 with evacuation. The higher value during evacuation results from the fact that automobiles afford less shielding than buildings. (A ground roughness factor of 0.7 is included in the Reactor Safety Study shielding values.) Regulatory Guide 1.109 suggests a structural shielding factor of 0.7 for exposure of individuals and 0.5 for exposure of populations. A review of current literature will be made to determine appropriate values to use. (A ground roughness factor of 0.5 is included in the dose factors for standing on contaminated ground given in Table E-6 of Regulatory Guide 1.109.)

The time of exposure to the contamination is also significant. When evacuation is not postulated, average occupancy values may be used for a particular location. If evacuation is assumed, the exposure time will be significantly reduced, but it is then desirable to consider plume trajectory and evacuation route concurrently when determining the effective exposure time. Since evacuation is not likely to be needed for accidents of classes 3 through 8 little attention will be given to evacuation model improvements.

\subsubsection{Ingestion of Farm Products}

The airborne exposure mode can result in contamination of farm products including vegetables, fruit and animal products. Vegetation can be contaminated by both direct deposition and by root uptake from contaminated soil. Animal products including meat and milk (and milk products) are contaminated through ingestion of contaminated pasture, grains and hay by 1 ivestock. All of these pathways are considered in the routine release models of Regulatory Guide 1.109 and the accident models of the Reactor Safety Study. Although the Reactor Safety Study uses a simplification which groups all farm products into two categories - milk and all others. 
The potential dose for this pathway can be estimated by considering sequentially the factors influencing uptake and transport to man. The important factors to be considered are:

- Fraction of initial deposition retained on plants

- Resuspension onto foliar parts of plants

- Translocation of direct deposition from surfaces to edible parts of plants

- Removal of initial deposition from vegetation by weathering,

- Plant/soil concentration factor

- Change in availability from soil to roots with time

- Month of plowing, crop appearance, harvest

- Delay time between harvest and consumption

- Consumption by man

Concentrations in animal products are dependent on the quantity of animal food consumed and the concentrations in the feed crops; the latter are controlled by the factors listed above for food crops. Additional factors include:

- Intake by animal of contaminated food (consumption rates)

- Transfer of radionuclides to various animal products,

- Delay time between slaughter or collection (as in the case of milk and egg consumption).

Generic values for most of these factors are given in Regulatory Guide 1.109, which should be used only when site-specific values are unavailable or questionable. For accidental releases transient effects of some of the above factors will also have to be considered.

The Reactor Safety Study uses simple models to determine intake by man. The models calculate intake via the milk pathway per unit deposition of iodine, strontium, and cesium nuclides directly on to forage for direct deposition, and for strontium and cesium for the soil-forage-milk pathway. The contributions from other pathways (ingestion of vegetables, meat, etc.) are considered by applying a factor to the milk intake factors. 
This approach may or may not be sufficient considering the complexity of the transfer pathways and the difficulty in determining appropriate transfer parameters. In extension of these models to accidents of classes 3-8, it will be necessary to determine that iodine, strontium and cesium are indeed the critical nuclides in each release inventory and that the use of a simple two group model is appropriate. A more detailed food chain analysis should be made to determine the relative importance of nuclides in Classes 3-8 accident source terms.

The land usage in the vicinity of a given site is an important factor in determining intake from the farm product pathway. The Reactor Safety Study uses average data on a state-by-state basis to determine dairy production and farm crop production. Each spatial interval is assigned a state code and the corresponding usage parameters. It would be a simple matter to change the state usage data base values to site-specific land usage values. The models used in the Reactor Safety Study and Regulatory Guide 1.109 are discussed briefly in the following paragraphs.

The fraction of deposited material retained on edible portions of vegetation is assumed to be $50 \%$ in the Reactor Safety Study. This is a compromise value based on a review of literature. Reported values range from $6 \%$ to $85 \%$ and depend on vegetation type, density, rainfal1, and on the chemical and physical form of the contamination. In Regulatory Guide 1.109 this fraction was taken to be 1.0 for "icdines" and 0.2 for "other particulates" when calculating concentrations on forage, leafy vegetable and other produce (for sprinkler irrigation using contaminated water it was taken to be 0.25 for al1 nuclides.) A possible refinement for this study would be to define the initial deposition fraction as a function of radionuclide and possibly vegetation type as was done in Regulatory Guide 1.109 or as given in Chamberlain's work (1970).

In the Reactor Safety Study removal of contamination from plants by weathering is assumed to have a 14-day half-life applied to $85 \%$ of the material and a constant retention of $15 \%$. 


$$
f_{w}=0.85 \exp (-0.693 t / 14)+0.15
$$

where

$$
\begin{aligned}
& f_{w} \text { is the fraction of deposited material remaining on vegetation } \\
& \text { at } t \text { days after deposition. }
\end{aligned}
$$

Literature on weathering indicates that the half-life may be longer under poor growing conditions (i.e., during winter or in arid regions) and at times beyond a month or two after initial deposition. A refinement of the weathering mode 1 however, may not be appropriate for this study. In Regulatory Guide $1.109100 \%$ of the deposited nuclides were assumed to be removed from vegetation with a half-life of 14 days.

The soil-forage-milk pathway in the Reactor Safety Study is estimated by a simplification of the model of Booth, et al. (1971) a diagram of which is shown in Figure 1. Each compartment of the model is assumed to have exponential clearance. Transfer coefficients are presented for strontium and cesium. This model is probably sufficient for this study but should be extended to other nuclides as appropriate. The model could also form the basis of other soil-crop-man pathways which are not explicitly considered in the Reactor Safety Study if the transfer parameters, between compartments could be developed.

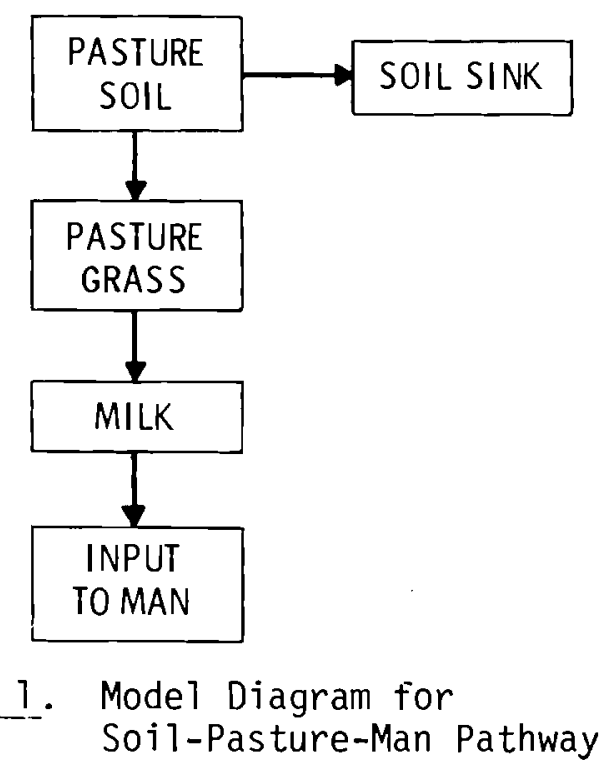




\subsubsection{Inhalation of Resuspended Material}

In calculation of the inhalation dose from resuspension, some fraction of the ground contamination is assumed to become airborne and be inhaled by persons in the immediate vicinity. The Reactor Safety Study uses the following model to estimate the resuspension of material.

$$
k(t)=10^{-5} \exp (-\lambda t)+10^{-9}
$$

where

$$
\begin{aligned}
& k(t) \text { is the resuspension rate }\left(\mathrm{Ci} / \mathrm{m}^{3}\right) /\left(\mathrm{Ci} / \mathrm{m}^{2}\right) \text { at time } \mathrm{t}, \\
& \lambda \text { is the resuspension factor decay constant, } 0.677 \mathrm{yr}^{-1}, \\
& \text { corresponding to a half-time of about one year. }
\end{aligned}
$$

A more recent evaluation of plutonium resuspension by Anspaugh, et al. (1975) has suggested the following form:

$$
k(t)=10^{-4} \exp (-\lambda \sqrt{t})+10^{-9}
$$

where

$$
\begin{aligned}
& \lambda \text { is } 0.15 \text { in units of }(\text { day })^{-1 / 2}, \\
& t \text { is time since deposition (days). }
\end{aligned}
$$

The characteristics of the Anspaugh model are: 1) the half-time of decrease during the first 10 weeks is 5 weeks, doubling over the next 30 weeks, 2) the initial resuspension factor is $10^{-4} \mathrm{~m}^{-1}$, and 3) the resuspension factor after 17 years and beyond is $10^{-9} \mathrm{~m}^{-1}$.

These models do not consider dependence of resuspension rate on soil roughness or vegetative cover. Such factors could have a significant effect on resuspension. However, characterization of these factors is not presently at a state where model modification is warranted. 


\subsection{WATERBORNE PATHWAYS}

The most important waterborne pathways summarized for this study are:

- External dose from swimming and boating

- External dose from shoreline deposition

- Internal dose from ingestion of drinking water

- Internal dose from ingestion of aquatic foodstuffs

- Internal dose from ingestion of irrigated farm products.

The external dose from deposition of waterborne radionuclides in irrigated fields may be calculated using the program FOOD (Baker, et. a1., 1976) with modifications for acute releases.

The discussion below describes the methodology of Regulatory Guide 1.109.

\subsubsection{External Dose from Swimming and Boating}

Persons exposed to contaminated waters (usually in recreational pursuits such as swimming, boating or skiing) may receive a direct radiation dose from contaminated waters. The dose received will depend on delay between release from source and exposure and the duration of exposure. These factors depend on the habits of the persons involved and are usually site dependent. However, generic values for average and maximum persons to be used in lieu of site specific data are given in Regulatory Guide 1.109.

For a given duration of exposure persons swimming (total immersion) receive a higher dose by a factor of 2 than those boating or water skiing (partial immersion or surface activities) because of the assumed spherical and hemispherical geometry, respectively.

External exposure from this pathway would be reduced by any evacuation undertaken following the accident. In the observed evacuation restrictions on access to the contaminated water would effectively reduce this exposure pathway. 


\subsubsection{External Dose from Shoreline Deposition}

Radionuclides deposited on the shores of rivers, lakes, or oceans may accumulate over a period of time leading to external irradiation of persons standing on contaminated surfaces. The amount of the nuclides built up on the shorelines depends on the concentration in the water, the depth of deposit, and the period of buildup. Then the dose to persons will depend on the time period spent on the contaminated surfaces assuming a specified height (usualiy one meter) above the surface.

The concentration in shoreline sediments has been estimated from an empirical equation derived by Soldat et. a1., (1974) from measurements on water and sediment concentrations on the Columbia River. The relationship as:

$$
s_{i}=100 \tau_{i} A_{i} W\left(1-e^{-\lambda_{i} t} s\right)
$$

where

$s_{i}$ is the "effective" surface contamination $\left(\mathrm{pCi} / \mathrm{m}^{2}\right)$ down to $3 \mathrm{~cm}$ depth.

100 is the emperical factor $\frac{\ell}{m^{2}-d}$

$\tau_{\boldsymbol{i}}$ is the radiological half-life of nuclide $i$ (d)

$A_{i}$ is the concentration of $i^{\text {th }}$ nuclide in water adjacent to sediment $(\rho \mathrm{C} / \ell)$

$W$ is the shore width factor (dimensionless)

$\lambda_{\boldsymbol{i}}$ is the radiological decay constant, $\frac{.693}{\tau_{\boldsymbol{i}}}\left(\mathrm{d}^{-1}\right)$

$t_{s}$ is the time of buildup $(d)$

The "shore-width" factor, $W$, corrects for the finite width of a contaminated surface. For wide areas such as tidal basins and fields, it would be $\sim 1$; whereas for narrower areas such as a river shoreline, it would be about 0.5 . The above expression is for a chronic release wherein $A_{j}$ is constant over the time period $t_{s}$. For accidental releases a transient buildup and removal model would be more appropriate provided necessary parameters are available or the above model applied as indicated in the Liquid Pathway Generic Study (LPGS). 


\subsubsection{Ingestion of Drinking Water}

Water containing radionuclides may be consumed by persons via municipal water supplies, wells, or direct withdrawal from a body of fresh water. In general, the dose to a person is dependent on the concentration of the nuclide in the water and the quantity of water ingested. The concentration is dependent on the amount of dilution in the receiving water, the time between release and ingestion, and any municipal water treatment process used, which may remove a large fraction of the radionuclides. Some data is available on water plant removal factors for a few sites (Denham and Soldat, 1975; Corey and Boni, 1975) and could be extended to other sites that use similar water treatment processes.

\subsubsection{Ingestion of Aquatic Foodstuffs}

Persons eating aquatic foods such as fish, clams, crabs, etc., harvested from waters contaminated with radionuclides, will receive internal radiation doses. Factors affecting these doses are the concentration of radionuclides in the water, bioaccumulation or concentration factor of the radionuclide in the organism over that in the water, the time between release and ingestion, and the amount of food ingested.

Bioaccumulation factors currently in use by the NRC are specified in Regulatory Guide 1.109 and were taken principally from Freke, (1967) and Thompson et a1. (1972).

The buildup of radionuclides in the aquatic organisms may sometimes be less following an accidental release than following a chronic release, depending upon the hydrology of the particular water body involved. Special time dependent models may need to be used to estimate potential exposure from aquatic foods for acute releases. However, very 1 imited data on rates of accumulation of radionuclides by aquatic organisms is available. It appears that the half-time of accumulation of some radionuclides by aquatic organisms may be shorter than the half-time for release of the acquired nuclide once the water concentration is reduced. This fact is accounted for in the LPGS model. 


\subsubsection{Ingestion of Irrigated Farm Products}

Terrestrially grown foods such as vegetables, fruits, and grains, and animal products such as milk and meat will contain radionuclides afiter irrigation with contaminated water. Persons consuming these products will receive a radiation dose, which is dependent on the amount consumed and the radionuclide concentrations in the foods.

The radionuclide concentrations in food crops and animal products contaminated via irrigation depend upon the same list of factors given before in Section 4.1 .4 for contamination via deposition from the atmosphere. In addition, several other factors are involved. These include:

- Concentration in irrigation water and buildup in soil

- Fraction of deposition retained on plants

- Irrigation rate, timing and type (e.g., flooding or sprinkling)

- Intake by animal of contaminated water (consumption rates).

\subsection{DIRECT DOSE}

The direct dose from contamination contained within the nuclear facility is calculated from the flux of radiation at the exposure points using appropriate dose conversion factors. The flux is calculated in the transport portion of the model as discussed in Section 3.4 above. Additional factors to include are structural shielding near the exposure point, exposure time and effects of evacuation. 


\subsection{DOSIMETRIC MODELS}

This section describes models used to calculate radiation dose from external radiation or from intake via ingestion or inhalation. These models are usually implemented by calculating dose factors normalized to air concentration or to intake for each nuclide of interest. This approach has been taken by all of the methodologies reviewed. The models for external exposure are discussed first followed by internal dosimetry models for ingestion and inhalation.

\subsection{EXTERNAL DOSIMETRY}

Exposure to radiation external to the body is considered for submersion in contaminated air and from exposure to contaminated ground (or shoreline). Dose calculations are based on dose conversion factors relating media concentration to dose for skin, total body and internal organs of interest. For air submersion radiation dose may be received from both gamma and beta emissions: alpha radiation does not have sufficient penetrating power in air or tissue to be of concern. Beta dose is calculated by:

$$
D_{\beta}(0)=0.23 \bar{E}_{\beta} E
$$

where

$$
\begin{aligned}
& D_{\beta}(0) \text { is the beta dose at the tissue surface (rad), } \\
& \bar{E}_{\beta} \text { is average beta energy emitted per disintegration } \\
& \text { (MeV/disintegration), } \\
& E \text { is the time integral of air concentration ( } \mathrm{Ci} \mathrm{sec} / \mathrm{m}^{3} \text { ), } \\
& 0.23=(0.5) \frac{\left(1.6 \times 10^{-6} \frac{\mathrm{ergs}}{\mathrm{MeV}}\right)\left(3.7 \times 10^{10} \frac{\mathrm{dis}}{\mathrm{Ci} \mathrm{sec}}\right)}{\left(1293 \mathrm{~g} / \mathrm{m}^{3}\right)}\left(\frac{\mathrm{rad}}{\mathrm{dis} \mathrm{m}^{3}}\right)
\end{aligned}
$$


- The factor 0.5 is to account for self shielding of the body from half of the contaminated air.

Equation 21 gives the beta dose to tissue at the body surface. This expression is recommended by the methodology of Regulatory Guides 1.3 and 1.4. Regulatory Guide 1.109 recommends use of an additional factor (Loevinger et a1., 1956), to account for reduction of beta dose during penetration of $7 \mathrm{mg} / \mathrm{cm}^{2}$ tissue. This is the depth of the basal layer cells of the epidermis (U.S. Department of Commerce, 1954). (a) The Reactor Safety Study did not consider skin exposure to be a significant health risk and, therefore, did not consider beta radiation for external exposure.

The gamma dose to the body from air submersion is calculated in the Regulatory Guides using the semi-infinite cloud assumption in a manner similar to the beta skin dose calculation, except that the factor of 0.5 now accounts for the fact that the ground interface makes the air source effectively semiinfinite. The expression for the gamma dose is:

$$
D_{Y}(0)=0.23 f_{Y} \bar{E}_{Y} E
$$

where

$D_{\gamma}(0)$ is the gamma dose contribution at the surface of the body (rem),

$\bar{E}_{Y}$ is the effective gamma energy released per disintegration (MeV/dis),

$E$ is as defined for Equation 21,

$f_{Y}$ is the stopping power of tissue relative to air for the gamma energy.

The factor $f_{Y}$ is assumed to be constant at 1.11. The surface dose is modified in Regulatory Guide 1.109 by an exponential attenuation factor to calculate the total-body dose at a tissue depth of $5 \mathrm{~cm}$.

(a) The current practice of the USNRC Division of Site Safety and Environmental Analysis (DSE) staff for calculation of the skin dose from external exposure is to sum this reduced beta dose and the surface gamma dose given by Equation 22. 


$$
D_{\gamma}(5)=D_{\gamma}(0) \exp (-5 \mu)
$$

where

$$
\begin{aligned}
& D_{\gamma}(5) \text { is the dose at a tissue depth of } 5 \mathrm{~cm}(\mathrm{rem}), \\
& \mu \text { is the total linear energy attenuation coefficient for } \\
& \text { tissue, }\left(\mathrm{cm}^{-7}\right) .
\end{aligned}
$$

The dose to internal body organs is assumed to be equal to the total-body dose. In performing the calculation, dose factors are used which convert directly from time-integrated air concentration to dose. Regulatory Guide 1.109 presents the external dose conversion factors for air submersion for noble gases. For free standing stacks over 80 meters high the dose conversion factors are to be modified to account for the finite dimensions of the plume (see section 4.1.1).

The Reactor Safety Study uses dose conversion factors for air submersion based on Monte Carlo calculations of Poston and Snyder (1974) for a phantom. These dose conversion factors are calculated for each organ of interest as a function of the photon energy emitted in the semi-infinite cloud.

Air submersion, dose conversion factors presented in the Reactor Safety Study agree quite well with those calculated by the model of Regulatory Guide 1.109 for total body. Also, the dose factors of the Reactor Safety Study do not vary a great deal among the organs of interest except for a few nuclides with low gamma energies and for the lung where the factors are generally lower than the total-body dose.

Exposure to contaminated ground is calculated by assuming the ground surface to be an infinite disk source with the receptor at one meter above the surface. This model is used by both the Regulatory Guide 1.109 and the Reactor Safety Study. Regulatory Guides 1.3 and 1.4 do not consider ground contamination. 
The gamma dose rate at a distance d above an infinite disk source is given by:

$$
D_{\gamma}(0)=824 C_{i} B E_{1}\left(\mu_{i} d\right) \mu_{a i} E_{\gamma i} f_{i}
$$

where

$D_{\gamma}(0)$ is the gamma dose rate in air at a distance d meters above ground ( $\mathrm{rad} / \mathrm{hr}$ ),

$C_{i}$ is the source strength (curies $\mathrm{m}^{-2}$ ),

$B$ is the buildup factor for photons of energy $i$ in traversing 1 meter of air ( $B$ is essentially equal to unity),

$E_{1}\left(\mu_{j} d\right)$ is the first exponential integral function (Kovalev and Foderaro, 1968) evaluated at $\mu_{i} d$

$\mu_{i}$ is the linear attenuation coefficient for photons of energy $i$ in air $\left(\mathrm{m}^{-1}\right)$,

$\mu_{a j}$ is the energy absorption coefficient for photons of energy $i$ in $\operatorname{air}\left(\mathrm{m}^{-1}\right)$,

$E_{\gamma i}$ is the photon energy (MeV/photon),

$f_{i}$ is the abundance of photons of energy $i$ for the source (photons/dis).

$824=\frac{1}{2}\left(3.7 \times 10^{10} \frac{\mathrm{dis}}{\mathrm{Ci} \mathrm{sec}}\right)\left(1.6 \times 10^{-6} \frac{\mathrm{erg}}{\mathrm{MeV}}\right)\left(\frac{\mathrm{g} \mathrm{rad}}{100 \mathrm{erg}}\right)\left(\frac{3600 \mathrm{sec}}{\mathrm{hr}}\right)\left(\frac{\mathrm{m}^{3}}{1293 \mathrm{~g}}\right)$

The factor of one-half is the constant of integration based on the infinite disk source geometry.

In the Reactor Safety Study the air dose rate was converted to internal organ dose rate using the same dose ratio factors developed for air submersion even though the gamma energy spectrum is not quite the same at one meter above ground as it is in the semi-infinite cloud, (Poston and Snyder, 1974). 
A backscatter factor of 1.14 was also applied to account for reflection from the ground. However, this particular factor appears to be superfluous, since emperical data relating measured dose rates from fallout contaminated ground to theoretical doses from a disk source yielded 0.7 including both self shielding and backscatter from the rough ground (Clifford, 1963, Ferguson, 1963, Bennet, et.a., 1967).

In Regulatory Guide 1.109 the tissue dose is calculated by multiplying by the stopping power of tissue relative to air, $f_{\gamma}$, as defined above. The value of $f_{\gamma}$ varies from 1.05 to 1.11 over the range of gamma energies of .01 to $10 \mathrm{MeV}$. Then an exponential tissue penetration factor for $5 \mathrm{~cm}$ of tissue was applied to obtain the total-body dose. A factor of 0.5 was also applied to account for ground roughness.

The Reactor Safety Study dose conversion factors for exposure to ground contamination give total-body doses approximately twice as high as the dose factors in Regulatory Guide 1.109. The difference is primarily due to the factor of 0.5 for ground roughness used in the Regulatory Guide values versus the factors of 0.7 for ground roughness and 1.14 for backscatter.

\subsection{INTERNAL DOS IMETRY}

The pathway models discussed in Section 4 provide contamination levels in the air and foodstuffs reaching the population. internal dosimetry models are used first to convert the contamination levels to intake via inhalation and ingestion. Next the models convert intake into radiation dose to body organs for given intake and dose periods. In order to determine dose from intake, it is necessary for the models to describe organ uptake, translocation, deposition and elimination of radioactivity within the body.

Details of the ingestion and inhalation models are given in the following sections. 


\subsubsection{Gastrointestinal Tract Dosimetry Models}

Models used to describe the dosimetry of the gastrointestinal tract consider four distinct compartments: stomach, small intestine, upper large intestine and lower large intestine. The ingested material enters through the stomach and travels sequentially through each compartment. Absorption of material into the blood is only considered to occur in the small intestine.

The model presented in ICRP Publication 2 and used for the dose conversion factors found in Regulatory Guide 1.109 assumes that material entering the stomach resides there for one hour and then moves in a batch to the small intestine. Flow through the small intestine and large intestine is assumed to be continuous and linear. The critical tissue in the intestine is considered to be the wall. The dose is therefore calculated as one-half the dose to the mass of the contents. For alpha radiation a factor of 0.01 is also applied to the effective energy to account for the ineffectiveness of alpha particles in reaching the sensitive cells of the stomach and intestine walls.

The gastrointestinal tract model used in the Reactor Safety Study is taken from Snyder et a1., (1974) with parameters from ICRP Publication 23 (1975). In this model each of the four compartments are characterized by exponential emptying in sequence. The average dose to the entire length of the wall of each compartment is calculated from the activity using factors of Snyder et al., (1974) based on Monte Carlo type calculations. This model is mathematically quite different from the model of ICRP Publication 2. The ICRP model assumes a batch flow through the stomach and linear (plug) flow through the remaining three compartments. In addition, the latter model calculates the dose only at the entrance to each of the intestine compartments, since these are normally the most highly exposed portions of the wall.

A reasonable method for calculating dose to gastrointestinal tract compartments would be to use the initial ICRP modes (bulk removal from stomach and linear flow through the intestines) with updated mean transit times and mass values from ICRP Publication 23. 


\subsubsection{Inhalation Dosimetry Models}

Two inhalation models have been presented by ICRP: the initial ICRP lung model (ICRP, 1959) and the lung model of the Task Group on Lung Dynamics (Morrow, 1966 and ICRP, 1972). The initial lung model was used to calculate dose conversion factors found in Regulatory Guide 1.109. This model is also recommended to be used for iodine inhalation dose calculations by Regulatory Guide 1.3 and 1.4. The Reactor Safety Study used the Task Group Lung Mode1 (TGLM). Details of both of these models are described briefly below. In both models, a fraction of inhaled material initially deposited is subject to ciliary-mucus transport and is subsequently swallowed. The swallowed material is thereafter treated in the same manner as ingested material (see Section 5.2.1).

The initial ICRP lung model provides a general model for intake of radionuclides into the body. The distribution of inhaled particulate material within the body is described for two classes of compounds: readily soluble compounds and insoluble compounds. For both classes of compounds it is assumed that $25 \%$ of the inhaled material is quickly exhaled, $50 \%$ is deposited in upper respiratory passages (and subsequently swallowed) and the remaining $25 \%$ is deposited in the lungs. For insoluble compounds half of the amount deposited in the lungs is assumed to be swallowed in the first 24 hours and half is assumed to remain in the lungs with a 120-day half-life (except for plutonium and thorium which have 1-year and 4-year half-lives respectively). The total amount of insoluble material swallowed (i.e., that reaches the GI tract) is then $62.5 \%$. Material classed as "insoluble" is not absorbed from the small intestine and only the GI tract receives a radiation dose.

For readily soluble compounds $50 \%$ reaches the GI tract. The $25 \%$ initially deposited in the lung is assumed to be taken.up immediately into the body (via the blood). The total amount reaching an organ is then given by:

$$
f_{a}=\left(0.25+0.5 f_{1}\right) f_{2}^{\prime}
$$


where

$f_{a}$ is the fraction of that taken into the body by inhalation that reaches the organ of interest,

$f_{1}$ is the fraction of the radionuclide passing from the GI tract to the blood,

$f_{2}^{\prime}$ is the fraction passing from the blood to the organ.

The mathematical model for calculating the dose to an organ of interest via inhalation using the ICRP Task Group Lung Model, TGLM, is considerably more complex than that utilized by the lung model initially recommended by the ICRP. In the TGLM, the respiratory tract is divided into three regions, the nasopharyngeal (NP), the tracheobronchial (TB), and the pulmonary ( $P$ ). Deposition is assumed to vary with the aerodynamic properties of the aerosol distribution and is described by the three parameters $D_{3}, D_{4}$ and $D_{5}$. These parameters represent the fraction of the inhaled material initially deposited in the NP, TB and $P$ regions, respectively. Each of the three regions of depostion are further subdivided into two or more subcompartments, each representing the fraction of material initially in a compartment that is subject to a certain clearance process. Material is cleared from the subcompartments to the blood, lymphatic system or GI tract. A portion of the material entering the lymphatic system and the GI tract may also reach the blood. Transport of the radionuclides from the respiratory tract, lymphatic systems, and GI tract to other organs and tissues where significant accumulations of the inhaled radionuclide occur, is assumed to take place via the blood. This translocation from the respiratory tract and lymphatic system to the blood has been described in considerable detail (Morrow, 1966). A constant fraction of any "soluble" material clearing from the respiratory tract through the GI tract is assumed to be taken up by the blood while passing through the small intestine as described in the previous section on ingestion models. 
The calculation of doses from inhalation of particulate material should be based on the TGLM since this model was developed specifically for this purpose. To use the TGLM for vapor and gases would require a knowledge of the deposition characteristics of the material involved. If this information is not available, use of the initial lung model would be more appropriate.

\subsubsection{Dosimetry Models for Other Organs}

The ingestion and inhalation models describe uptake and translocation of material to other organs. Elimination from the organs is described by esponential expressions in both the Regulatory Guide 1.109 and Reactor Safety Study models. The Regulatory Guide 1.109 model uses a single exponential model, while the Reactor Safety Study uses from one to five exponential terms depending on the radionuclide and organ under consideration.

The dose to an organ is proportional to the total radiation energy deposited in the organ from radioactive decay of the nuclide. The model used to calculate the dose conversion factors in Regulatory Guide 1.109 was that found in ICRP Publication 2 (ICRP, 1959). In this model all of the radionuclide is assumed to be located in the center of a spherical organ of proper effective radius. All particle radiations emitted are absorbed within the organ; all photon radiations are partially absorbed depending upon the organ radius and photon energy. The potential contribution to organ dose from photon radiation originating outside of that organ is ignored.

The doses calculated for the Reactor Safety Study included the contribution to a "target" organ from photons originating from atoms of the radionuclide decaying in other "source" organs. These contributions had previously been calculated by a Monte Carlo method using a phantom containing more realisticality shaped organs (Snyder et al., 1974).

Inhalation and ingestion dose factors are generally of the same order of magnitude for the two methodologies. Disagreement is due mainly to the differences in metabolic models used, including organ uptake and retention parameters. Most other factors affecting internal dose computations were treated similarly by the two methodologies. 



\subsection{HEALTH EFFECTS}

This section summarizes methods used by the Reactor Safety Study to estimate health effects from the calculated doses. Three categories of health effects are considered: early somatic effects, late somatic effects and genetic effects. Models for each of these effects are summarized below with an indication given of modifications necessary to include doses from the direct radiation and waterborne exposure modes.

\subsection{EARLY SOMATIC EFFECTS}

Early somatic effects include mortalities and morbidities that occur within a matter of days and up to one year after exposure. These effects generally involve doses of 100 rads or more. The Reactor Safety Study has determined that the only organs of significance for estimating early mortalities are bone marrow, lung and gastrointestinal tract. The health effects are based on the dose received within a specified time period with contributions from the following pathways:

- External dose from the passing cloud

- External dose from ground contamination, and

- Internal dose from inhalation.

Since the time of cloud passage is small (one-half to several hours) the total dose from cloud passage is included. Evacuation may reduce the time of exposure to the cloud. The time period for calculation of external dose from contaminated ground depends on the location of the individual and whether evacuation or relocation occurs. If a person is within 25 miles $(40 \mathrm{~km})$ of the reactor, an exposure time of 4 hours is used whenever evacuation occurs. At distances beyond 25 miles $(40 \mathrm{~km})$, or for non-evacuated people within 25 miles, the exposure time is 7 days unless immediate relocation occurs in which case the exposure time is one day. The time period for internal exposure depends on the organ being considered, as follows: 
Bone Marrow: includes internal dose within 7 days after the accident plus one-half of the dose received between 8 and 30 days from inhalation of radionuclides.

Lung: includes internal dose received within one year from inhalation of radionuclides.

Gastrointestinal tract: includes internal dose received within 7 days.

The calculation of early morbidities is based on respiratory impairment resulting from exposure to sublethal doses. The effects are based on the lung dose as calculated above for early mortalities. Other effects are considered but are concluded to be much less significant.

The conversion of organ doses to early mortalities and morbidities is based on the relationship between dose and the probability of observing the effect of interest. The number of effects is calculated as the product of the probability of the effect and the number of people receiving the specified dose. The Reactor Safety Study presents dose/effect curves based on available data with consideration given to potential mitigation of effects resulting from medical treatment.

The addition of waterborne and direct radiation exposure modes to the analysis will require modification of the estimated doses. The direct irradiation exposure is similar to the ground contamination exposure. The exposure time would depend on location, evacuation, relocation and any phenomena causing the source strength to be reduced (decay or cleanup). Waterborne releases could cause internal exposure from ingestion of drinking water, aquatic foods, and irrigated farm products if interdiction is not employed. External exposure from contaminated shoreline and from swimming and boating may also be received.

\subsection{LATE SOMATIC EFFECTS}

The calculation of late somatic effects is limited to latent cancer fatalities plus benign and cancerous thyroid nodules. Because of the 
randomness of these effects, the Reactor Safety Study based the calculation of late somatic effects on population doses. Late somatic effects are based on early (acute) uptake plus uptake in years following the accident (chronic).

Three models are available for estimating late somatic health effects. The central estimate method is thought to provide the most likely values of health effects. An upper bound and lower bound may also be determined to indicate the expected range of health effects. The upper bound is based on data from the BEIR Report (1972). The central estimate is derived from the upper bound by applying dose-effectiveness factors defined as a function of total dose and dose rate. The lower bound is determined by applying a threshold dose below which no health effects are realized.

The basic model for calculating cancer fatalities assumes a latent period in which no effects are found. Following this period is a plateau period during which the incidence rate is assumed to be constant; no effects are assumed to occur after the plateau period. The conversion of dose to health effects is done as a function of time with consideration given to the age distribution within the population. Time periods suggested are 0-1 year, 1-10 years, 11-20 years, etc., out to 80 years. Dose factors are provided in a data library for each nuclide, each organ and each of the above time periods for a unit acute uptake.

To extend this model to waterborne pathways, it would be necessary to include organ doses calculated via waterborne ingestion pathways. Some of the ingestion pathways can continue to contribute to intake over a period of years. Contributions from the direct irradiation pathway would probably be received within a short time after the accident.

The Reactor Safety Study calculates thyroid nodule occurence for both benign and malignant cases. The occurence rates (per man-rem) decrease with increasing dose with benign nodules being slightly more likely than cancerous nodules. A $10 \%$ mortality rate for thyroid nodules is assumed based on the incidence of malignant nodules. The dose is calculated as the sum of: 
- External dose from the passing cloud

- External dose from ground contamination

- Internal dose during the first 30 days from a11 nuclides except iodine-131, and

- $1 / 10$ of the internal dose within 30 days from iodine-131.

Contributions from direct exposure and waterborne pathways should be added to the above dose calculations.

\subsection{GENETIC EFFECTS}

The Reactor Safety Study considers genetic effects of four types:

- Autosomar dominant disorders,

- Multifactorial disorders,

- Disorders due to chromosomal aberrations, and

- Spontaneous abortions.

Frequency factors are developed for external and internal radiation as a function of time of accumulation of the dose after the accident. The expected effects are also expressed as a broad function of time by considering two consecutive 30 -year periods after the accident plus all remaining time. The frequencies are developed from data in the BEIR Report (1972). Consideration is given to both the age and sex of the exposed population since genetic effects are predominantly generated through irradiation of fathers.

Extension of the model to include direct irradiation and waterborne pathways should be done. 


\subsection{EVACUATION AND SHELTERING}

Evacuation or sheltering may be significant for accidents involving large airborne releases or possibly for large releases to containment where direct irradiation may be significant at locations close to the reactor. The need for evacuation or sheltering because of liquid releases is unlikely due to enhanced shielding from water sources and interdiction to prevent exposure. of the four methodologies reviewed, the only one to consider the impact of evacuation was the Reactor Safety Study. It did not, however, postulate any sheltering. The evacuation model used was applied uniformly at all reactor sites and in all directions. Specific site characteristics were not considered. This model is described below along with suggested areas for improvement needed for application of the model to site-specific analyses.

The evacuation model is used to estimate potential mitigation of early exposures and to provide input to the economic cost estimate. The model (as described in Appendix VI of the Reactor Safety Study) is based on data presented by Hans and Sel1 (1974) covering actual evacuation experience during the years 1959 through 1973. These evacuation data were analyzed for the Reactor Safety Study to determine the effective evacuation speed defined as:

$$
v=\frac{d}{t}
$$

where

$v$ is the effective evacuation speed (mph),

$d$ is the distance traveled (mi),

$t$ is the time from initial warning to the time the evacuation is complete $(h r)$.

The analysis showed that a log-normal distribution can be used to describe the effective evacuation speed. Three categories were selected to

model the range of evacuation speeds. It was assumed that $30 \%$ of the people would evacuate at $7 \mathrm{mph}, 40 \%$ at $1.2 \mathrm{mph}$ and $30 \%$ at $0 \mathrm{mph}$. These evacuation categories were applied to the population within a keyshaped area about the 
site centered on the direction of the sector of interest. The people affected included all those within five miles of the reactor (all directions) plus those out to 25 miles within a 45 degree sector centered on the downwind direction. All of the population within each speed category is assumed to start moving at the time of warning and travel at the same speed in a radial direction away from the site. If the contaminated plume should overtake the people, they are assumed to change direction and travel laterally. Under such circumstances (overtaken by plume) an exposure time to the plume of 4 hours is assumed.

Improvements to the Reactor Safety Study evacuation model for use on a site-specific basis and for lower class accidents may be possible in the following areas:

- Determination of the need for evacuation for lower class accidents,

- Expansion of the number of evacuation speed categories including a non-evacuating fraction,

- Identification of populations of limited mobility such as those at prisons or hospitals,

- Determination of probable direction of evacuation from local highway networks and natural barriers (rivers, mountains, etc.). The need for evacuation during accidents less severe than Class 9 is questionable. The Reactor Safety Study states that evacuation would not take place for accidents less severe than a core melt. However, the capability to evaluate the effect of evacuation should be retained in the model for the assessment of lesser accidents, to ensure its availability if needed. Also the capability to evaluate the effect of sheltering when appropriate, is desirable. 


\subsection{ECONOMIC COSTS}

The Reactor Safety Study estimated economic costs resulting from Class 9 accidents. None of the other methodologies attempted to estimate these costs. The major components of the Reactor Safety Study economic model were:

- Evacuation costs,

- Interdiction costs,

- Decontamination costs.

Each of these components are discussed in the sections below. The economic model developed for the Reactor Safety Study could be extended to accident Classes 3-8 by making a few modifications such as reevaluation of economic data to account for inflation and use of more specific data on crop type and land usage on a site-specific basis.

\subsection{EVACUATION COSTS}

The Reactor Safety Study evacuation model described in Section 7.0 was used to define mitigation of possible health effects and to estimate economic costs. Cost data from the EPA evacuation study by Hans and Sel1 (1974) were corrected for inflation and used to estimate the cost of evacuation. Costs were included for temporary food and shelter, transportation and evacuation personnel. Using the assumption that $80 \%$ of evacuees would use private transportation and mass care facilities, a unit daily cost per person was established. The cost was then applied to the number of people evacuated.

Any changes made in the evacuation model as suggested in Section 7.0 would have to be reviewed to determine corresponding changes in calculation of economic costs from evacuation. The amount of commercial lodging actually available should be assessed for each site.

\subsection{INTERDICTION COSTS}

Economic losses due to interdiction considered in the Reactor Safety Study included:

- Condemnation of agricultural products, 
- Removal of land from occupancy and/or production,

- Relocation of residents from interdicted land,

- Loss of natural resources.

Before estimating economic costs, it is first necessary to determine if a given action is required. The Reactor Safety Study determined the required actions from potential contamination levels and doses. Dose criteria were based on recommendations of the U.S. Federal Radiation Council (1965) and the British Medical Research Council (1975). Agricultural products (crops and milk) are considered to be condemned if the calculated contamination level is above the acceptable standard at the time of harvest. Higher cortamination levels dictate the necessity for land interdiction and/or relocation of residents.

Interdiction costs are based on those aspects of interdiction that result in economic losses. The loss from condemnation of agricultural products is the value of the crops. The cost of land interdiction is based on the market value of the land plus improvements. For interdiction extending over a period of years the cost is based on depreciation of improvements, increases in property values and the cost of maintaining ownership of the land (taxes). The cost of relocation is the sum of moving costs plus income loss. Moving costs include both household and business expenses. The income losses include salaries, proprietor's income and rental income. The income loss is only applicable during the period of resettlement (about 90 days).

In addition to losses from agricultural production, losses may be incurred from denial of access to natural resources such as coal, oil and minerals. Costs would be associated with loss of jobs locally and at distant processing centers. For energy-related resources additional jobs may be lost in energy-intensive industries.

\subsection{DECONTAMINATION COSTS}

The decontamination model of the Reactor Safety Study bases actions on contamination levels and potential decontamination factors. If the contamination level could be reduced to acceptable levels by available decontami- 
nation methods, then decontamination is deemed to be practical. Reduction of contamination levels due to radioactive decay is also considered. The model considers costs for decontamination of lands used for farming, residential, commercial and public activities.

The approach appears to be satisfactory but it will be necessary to integrate it with other model modifications (addition of waterborne pathways, etc.). Also economic parameters should be reevaluated on a site-specific basis. 


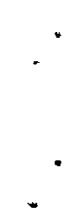




\subsection{SUMMARY OF AREAS NEEDING FURTHER EFFORT}

One of the goals of this review was to identify areas where model changes are needed in extension of the Reactor Safety Study Methodology designed for Class 9 accidents) to site-specific assessments for accidents of Classes 3-8. This section lists areas where model changes are practical and also areas where model changes may be considered in the future but are not practical or of significant effect at this time. Although not included in the lists below, it will also be necessary to reevaluate all parameters used by the various models on a site-specific basis. Items requiring attention at this time are:

- Direct irradiation from coritained activity should be included.

- Exposures from waterborne release pathways should be included.

- Dispersion sequences should be defined from hourly observation data for wind direction, wind speed, atmospheric stability and precipitation rate.

- More recent recommendations for plume rise equations should be used.

- Potential effects of terrain variations on dispersion calculations should be considered.

- Improved dry deposition models and experimental data for determination of deposition velocity for particulates, gases and iodine should be used.

- Wet deposition should be based on actual hourly precipitation rate data with particulates and gases handled separately. Implementation of this modification is dependent on availability of precipitation rate data on a site-specific basis.

- Finite cloud external gamma dose correction factor tables should be expanded to include functional dependence on lateral dispersion.

- Additional soil-crop-man pathways which were not explicitly included in the Reactor Safety Study should be considered.

- Transient behavior of nuclides in the terrestrial food chain should be included as data allows. 
- Ingestion pathway contributions for a11 nuclides should be reevaluated.

- Detailed site-specific data on land usage, crop production and water usage should be used.

- Demographic data adjusted to a specific year such as the midpoint of plant life (or end of plant life) should be used.

- Shielding factors for various activities and exposure situations should be reevaluated based on available literature.

The degree to which the above modifications are implemented will depend on an evaluation of the net benefit (model improvement) balanced against the effort (cost and time) required to make the modification.

There are additional areas of interest where further effort should be devoted in the future, however, they will not be considered in the present study for a variety of reasons (e.g., insufficient data, complexity of calculations, insignificant effect on results or no reasonable model available). This future effort might include the following areas of interest.

- Atmospheric dispersion models when used on a site-specific basis should include variable trajectory models as necessary.

- Dry deposition models that allow non-uniform plume depletion (with height) under stable conditions should be investigated.

- Differences in behavior among the chemical forms of iodine in transport and dosimetry models should be included.

- Preferential directional movements during evacuation based on sitespecific highway network information should be evaluated.

- Expansion of the number of evacuation speed categories (including a non-evacuating fraction) should be examined.

- Use of demographic data defined for periods of work and periods of sleep should be investigated.

- Limited mobility population groups (such as in hospitals and prisons) should be included in the evacuation model.

- Models for sheltering should be reviewed and an appropriate one included in the consequence evaluation model. 


\section{REFERENCES}

ANS Working Group 6.6 of ANS-6, Proposed American National Standard, "Calculation and Measurement of Direct and Scattered Gamma Radiation from Nuclear Power Plants." ANS-6.6.1, First Draft, December 1977. (This draft document is currently undergoing balloting for its possible adoption as ANSI-N346).

Anspaugh, L. R., J. H. Shinn, P. L. Phelps, and N. C. Kennedy, "Resuspension and Redistribution of Plutonium in Soils." Health Physics. Pergamon Press, 29:571-582, 1975

Baker, D. A., G. R. Hoenes and J. K. Soldat, "F00D - An Interactive Code to Calculate Internal Radiation Doses from Contaminated Food Products." Proceedings of the Conference on Environmental Modeling and Simulation, EPA 600/9-76-016 and BNWL-SA-5523, 1976.

BEIR Report, The Effects on Populations of Exposure to Low Levels of Ionizing Radiation, Report of the Advisory Committee on the Biological Effects of Ionizing Radiation, National Academy of Sciences National Research Counci1, Washington DC, 1972.

Bennett, C. B. , W. S. Kehrer, R. R. Soule and J. P. Corn, Gamma Ray Fields Above Rough Contaminated Surfaces, USNRDL-TR-68-20, U.S. Nava1 Radiologica1 Defense Laboratory, San Francisco, CA, 1967.

Booth, R. S., S. V. Kaye, and P. S. Rohwer, "A Systems Analys is Methodology for Predicting Dose to Man from a Radioactively Contaminated Terrestrial Environment." Proceedings of Third National Symposium on Radioecology, Oak Ridge, TN, May 10-12, 1971, U.S. Atomic Energy Commission CONF-710501, 1971.

Briggs, G. A., "Plume Rise." AEC Critical Review Series. TID-25075, Clearinghouse for Federal Scientific and Technical Information, Springfield, VA, 1969.

Briggs, G. A., Plume Rise Predictions. National Oceanic and Atmospheric Administration, June 1975.

Burson, Z. G., A. E. Profio, Structure Shielding From Cloud and Fallout Gamma Ray Sources for Assessing the Consequences of Reactor Accidents., EGG-1183-1670, EG\&G, Inc., Las Vegas, NV 1975.

Burt, E. W., "Valley Model User's Guide." EPA-450/2-77-018, U.S. Environmental Protection Agency Dispersion Program, available from the U.S. Environmental Protection Agency, Office of Air Quality Planning and Standards, Research Triangle Park, NC 27711, 1977.

Chamberlain, A. C., Atmospheric Environment. 4:57-78, 1970. 
C1 ifford, C. E., Effects of Ground Roughness on the $\gamma$-Dose from Cs-137 Contamination, Report No. DRCL-401, Defense Research Chemical Laboratories, Defense Research Board, 0ttawa, Canada, 1963.

Corey, J. C. and A. L. Boni, "Removal of Plutonium from Drinking Water by Community Water Treatment Facilities." IAEA-SM-199/81, Proceedings of the Transuranium Nuclides in the Environment, San Francisco, CA, PP. 401-408, November 17-21, 1975.

Denham, D. H. and J. K. Soldat, "A Study of Selected Parameters Affecting the Radiation Dose from Radionuclides in Drinking Water Downstream of the Hanford Project." Health Physics. 28:139-144, 1975.

Dunn, W. E., A. J. Policastro and R. A. Paddock, Surface Thermal Plumes: Evaluation of Mathematical Models for the Near and Complete Field. Parts One and Two, ANL/WR-75-3, Argonne National Laboratory, Energy and Environmental Systems Division, 1975.

Egan, B. A., "Turbulent Diffusion in Complex Terrain." In Lecture on Air Pollution and Environmental Impact Analysis--AMS Workshop on Meteorology and Environmental Assessment. American Meteorological Society, Boston, MA, PP. 123-124, 1975.

Engle, R. L., J. Greenborg and M. M. Hendrickson, ISOSHLD - A Computer Code for General Purpose Isotope Shielding Analysis. BNWL-236, Battelle, Pacific Northwest Laboratories, Rich1 and, WA 99352, 1966.

Engleman, R. J., "The Calculation of Precipitation Scavenging." In Meteorology and Atomic Energy - 1968, D. H. Slade, Editor, USAEC TID-24190, PP. 208-221, 1968 .

Federal Radiation Counci1, Background Material for the Development of Protective Action Guides for Strontium-89, Strontium-90 and Cesium-137.

FRC Staff Report No. 7, 1965.

Ferguson, J. M., Ground Roughness Effects for Fallout - Contaminated Terrain: Comparison of Measurements and Calculations, USNRDL-TR-645, U.S. Naval Radiological Defense Laboratory, San Francisco CA, 1963.

Freke, A. M., "A Model for the Approximate Calculation of Safe Rates of Discharge of Radioactive Wastes into Marine Environments." Health Physics, 13:743-758, 1967.

Gifford, F. A. Jr., "Atmospheric Transport and Dispersion Over Cities." Nuclear Safety, 13(5):391-402, 1972.

Hans, J.F. Jr., and T. C. Se11, Evacuation Risks - An Evaluation. EPA-520/6-74-002, U.S. Environmental Protection Agency, Nationa1 Environmental Research Center, Las Vegas, NV, 1974. 
Hirst, E., Analysis of Round, Turbulent, Buoyant Jet Discharged to Flowing Stratified Ambients, Report No. 4685, Oak Ridge National Laboratory, Oak Ridge, TN, 1971.

Hoenes, G. R. and J. K. Soldat, Age-Specific Radiation Dose Commitment Factors for a One-Year Chronic Intake. NUREG-0172, Battelle, Pacific Northwest Laboratories, for U.S. Nuclear Regulatory Commission, 1977.

ICRP, Report of Committee II on Permissible Dose for Internal Radiation/ International Commission on Radiological Protection, ICRP Publication 2 , Pergamon Press, 1959.

ICRP, Report of the Task Group on Reference Man. International Commission on Radiological Protection, Publication 23, Pergamon Press, New York, NY, 1975.

ICRP, The Metabolism of Compounds of Plutonium and 0ther Actinides. International Commission on Radiological Protection, Publication 19, Pergamon Press, New York, NY, 1972.

Jirka, G. H., G. Abraham and D. R. F. Harleman, Massachusetts Institute of Technology, An Assessment of Techniques for Hydrothermal Prediction. NUREG-0044, U.S. Nuclear Regulatory Commission, 1976. (Copies may be obtained from the National Technical Information Service, Springfield, VA.)

Jirka, G. H. and D. R. F. Harleman, The Mechanics of Submerged Multiport Diffusers for Buoyant Discharges in Sha110w Water. Report No. 169, Ralph M. Parsons Laboratory for Water Resources and Hydrodynamics, Massachusetts Institute of Technology, 1973.

Koh, R. C. Y. and L. N. Fan, Mathematical Models for the Prediction of Temperature Distributions Resulting from the Discharge of Heater Water In Large Bodies of Water. Report No. 161300W010/70, Water Pollution Contro1 Research Series, 1970.

Kovalev, E. E., and A. Foderaro, "Section 6.3 Surface Sources." Engineering Compendium on Radiation Shielding. Edited by R. G. Jaeger, Springer-Verlag, NY, 1968.

Lee, J. H. W., G. H. Jirka and D. R. F. Harleman, Stability and Mixing of a Vertical Round Buoyant Jet in Shallow Water. Report No. 195, Ralph M. Parsons Laboratory for Water Resources and Hydrodynamics, Massachusetts Institute of Technology, 1974.

Loevinger, R., E. M. Japha and G. L. Browne11, "Discrete Radioisotope Sources." Chapter 16, Radiation Dosimetry. Academic Press, Inc., 1956. 
Markee, E. H. Jr., "A Parametric Study of Gaseous Plume Depletion by Ground Surface Adsorption." Proceedings of USAEC Meteorological Information Meeting, C. A. Mawson, Editor, AECL-2787, PP. 602-613, 1967.

Medical Research Council. Criteria for Controlling Radiation Doses to the Public After Accidental Escapes of Radioactive Material. Her Majesty's Stationery Office, London, 1975.

Morrow, P. E., D. V. Bates, B. R. Fish, T. F. Hatch and T. T. Mercer, "Deposition and Retention Models for Internal Dosimetry of the Human Respiratory Tract." Health Physics. 12:173, 1966.

Pelletier, C. A. and J. D. Zimbrick, "Kinetics of Environmental Radioiodine Transport Through the Milk-Food Chain." Environmental Surveillance in the Vicinity of Nuclear Facilities, W. C. Reinig, Editor, Charles C. Thomas Publishers, Springfield, IL, 1970.

Poston, J. W. and W. S. Snyder, "A Model for Exposure to a Semi-Infinite Cloud of a Photon Emitter." Health Physics. 26:287-293, 1974.

Pritchard, D. W., "Design and Siting Criteria for Once-Through Cooling Systems." Presented at American Institute of Chemical Engineers, 68th Annual Meeting, Houston, TX, 1971.

Pritchard, D. W., "Fate of the Effect of Excess Heat Discharged into Lake Michigan with Specific Application to the Condenser Cooling Water Discharge from the Zion Nuclear Power Station." Testimony at the AEC Licensing Hearings for the Zion Nuclear Power Station Operating Permit, Chicago, IL, 1973.

Prych, E. A., "A Warm Water Effluent Analyzed as a Buoyant Surface Jet." Sveriges Meterologiska och Hydrologiska Institut, Serie Hydrologi, nr 21 , Stockholm, Sweden, 1972.

Rosen, L. C., A Review of Air Quality Modeling Techniques. LBL-5998, Lawrence Berkeley Laboratory, Berkeley, CA, 1977.

Sagendorf, J. F., A Program for Evaluating Atmospheric Dispersion from a Nuclear Power Station. NOAA Technical Memorandum ERL ARL-42, Air Resources Laboratory, Idaho Fal1s, Idaho, 1974.

Sagendorf, J. F. and J. T. Goll, XOQD0Q Program for the Meteorological Evaluation of Routine Effluent Releases at Nuclear Power Stations. Draft, NUREG-0324, U.S. Nuclear Regulatory Commission, Washington, DC 20555, 1977.

Shirazi, M.A. and L. R. Davis, Workbook of Thermal Plume Prediction, Volume 2 - Surface Discharge. Report No. EPA-R2-72-005b, U.S. Environmental Protection Agency, National Environmental Research Center, Environmental Protection Technology Series, Corvallis, OR, 1974. 
Slade, D. H., Meteorology and Atomic Energy. U.S. Atomic Energy Commission, Washington, DC, 1968.

Snyder, W. S., M. R. Ford, G. G. Warner and S. B. Watson, A Tabulation of Dose Equivalent per Microcurie-Day for Source and Target Organs of an Adult for Various Radionuclides. ORNL -5000 , Oak Ridge National Laboratory, Oak Ridge, TN, 1974.

Soldat, J. K., N. M. Robinson and D. A. Baker, Models and Computer Codes for Evaluating Environmental Radiation Doses. BNWL-1754, Battelle, Pacific Northwest Laboratories, Richland, WA, 1974.

Strenge, D. L., E. C. Watson and J. G. Droppo, Review of Calculational Models and Computer Codes for Environmental Dose Assessment of Radioactive Releases. BNWL-B-454, Battelle, Pacific Northwest Laboratories, Richland, WA $99352,1976$.

Stolzenback, K. D., E. E. Adams and D. R. F. Harleman, A User's Manual for Three-Dimensional Heater Surface Discharge Conditions. Report No. 156, Ralph M. Parsons Laboratory for Water Resources and Hydrodynamics, Massachusetts Institute of Technology, 1972.

Stolzenbach, K. D. and D. R. F. Harleman, An Analytical and Experimental Investigation of Surface Discharges of Heated Water, Report No. 135, Ralph M. Parsons Laboratory for Water Resources and Hydrodynamics, Massachusetts Institute of Technology, 1971.

Thompson, S. E., C. A. Burton, D. J. Quinn and Y. C. Ng, Concentration Factors of Chemical Elements in Edible Aquatic Organisms. UCRL-50564, Rev. 1, Lawrence Livermore Laboratory, Livermore, CA, October 10, 1972.

Trent, D. S., Mathematical Modeling of Transport Processes In Aquatic Systems, BNWL-SA-5379, Battelle, Pacific Northwest Laboratories, Richland, WA $99352,1975$.

USAEC, Assumptions Used for Evaluating the Potential Radiological Consequences of a Steam Line Break Accident for Boiling Water Reactors. Regulatory Guide 1.5, U.S. Atomic Energy Commission, Washington DC 20555, 1971.

USAEC, Assumptions Used for Evaluating the Potential Radiological Consequences of a Pressurized Water Reactor Radioactive Gas Storage Tank Failure. Regulatory Guide 1.24, U.S. Atomic Energy Commission, Washington, DC 20555, 1972a.

USAEC, Assumptions Used for Evaluating the Potential Radiological Consequences of a Fuel Handling Accident in the Fuel Handling and Storage Facility for Boiling and Pressurized Water Reactors. Regulatory Guide 1.25, U.S. Atomic Energy Commission, Washington, DC 20555, $1972 \mathrm{~b}$.

USAEC, Assumptions Used for Evaluating the Potential Radiological Consequences of a Loss of Coolant Accident for Boiling Water Reactors. Regulatory Guide 1.3, Rev. 2, U.S. Atomic Energy Commission, Washington, DC, 1974a. 
USAEC, Assumptions Used for Evaluating the Potential Radiological Consequences of a Loss of Coolant Accident for Boiling Water Reactors. Regulatory Guide 1.4, Rev. 2, U.S. Atomic Energy Commission, Washington, DC, 1974b.

USAEC, Assumptions Used for Evaluating a Control Rod Ejection Accident for Pressurized Water Reactors. Regulatory Guide 1.77, U.S. Atomic Energy Commission, Washington, DC 20555, $1974 \mathrm{C}$.

USNRC, Reactor Safety Study: An Assessment of Accident Risks in U.S. Commerical Nuclear Power Plants, Appendix VI, Calculation of Reactor Accident Consequences. WASH-1400 (NUREG 75/104), U.S. Nuclear ReguTatory Commission, Washington, DC 20555, 1975.

USNRC, Assumptions Used for Evaluating the Potential Radiological Consequences of a Radioactive Offgas System Failure in Boiling Water Reactor. Regulatory Guide 1.98, U.S. Nuclear ReguTatory Commission, Washington, DC 20555, 1976 a.

USNRC, Preparation of Environmental Reports for Nuclear Power Stations. Regulatory Guide 4.2, Rev. 2, U.S. Nuclear Regulatory Commission, Washington, DC 20555, 1976b.

USNRC, Calculation of Annual Doses to Man from Routine Releases of Reactor Effluents for the Purpose of Evaluating Compliance with 10 CFR Part 50 , Appendix I. Regulatory Guide 1.109, Rev. 1, U.S. Nuclear Regulatory Commission, washington, DC 20555, 1977a.

USNRC, Methods for Estimating Atmospheric Transport and Dispersion of Gaseous Effluents in Routine Releases from Light-Water-Cooled Reactors. Regulatory Guide 1.111, Rev. 1, U.S. Nuclear Regulatory Commission, Washington, DC 20555, 1977b.

USNRC, Estimating Aquatic Dispersion of Effluents from Accidental and Routine Reactor Releases for the Purpose of Implementing, Appendix I/ Regulatory Guide 1.113, Rev. 1, U.S. Nuclear Regulatory Commission, Washington, DC 20555, 1977c.

USNRC, Liquid Pathway Generic Study. NUREG-0440, U.S. Nuclear Regulatory Commission, Washington, DC 20555, 1978.

U.S. Department of Commerce, "Permissible Dose from External Sources of Ionizing Radiation." Handbook 59, 1954. 
PNL -2633

$\mathrm{RH}$

\section{DISTRIBUTION}

No. of

Copies

OFFSITE

1 A. A. Churm DOE Chicago Patent Group

Argonne, IL 60439

27 DOE Technical Information Center

Oak Ridge, TN 37830

169 Nuclear Regulatory Commission

Washington, DC 20555

Standard distribution under RH (146)

2 S. Acharya

U.S. Nuclear Regulatory Commission

Office of Nuclear Reactor Regulation

Washington, DC 20555

F. D. Anderson

U.S. Nuclear Regulatory Commission

Office of Standards

Development

Washington, DC 20555

W. S. Bivins

U.S. Nuclear Regulatory

Commission

Office of Nuclear Reactor Regulation

Washington, DC 20555

R. M. Blond

U.S. Nuclear Regulatory Commission

Office of Nuclear Regulatory Research

Washington, DC 20555
No. of

Copies
A. R. Buhl
U.S. Nuclear Regulatory Commission
Office of Nuclear Regulatory Research
Washington, DC 20555
D. F. Bunch
U.S. Nuclear Regulatory Commission
Office of Nuclear Reactor
Regulation
Washington, DC 20555

G. L. Chipman, Jr.

U.S. Nuclear Regulatory Commission

Office of Nuclear Reactor Regulation

Washington, DC 20555

F. Conge 1

U.S. Nuclear Regulation Commission

Office of Nuclear Reactor

Regulation

Washington, DC 20555

P. Donahoe

State of New Mexico

Environmenta 1 Improvement

Division

P.0. Box 968

Santa Fe, NM 87503

K. F. Eckerman

U.S. Nuclear Regulatory Commission

Office of Nuclear Reactor

Regulation

Washington, DC 20555 
No. of

Copies

E. E. Held

U.S. Nuclear Regulatory Commission

Office of Standards Development

Washington, DC 20555

R. W. Houston

U.S. Nuclear Regulatory Commission

Office of Nuclear Reactor Regulation

Washington, DC 20555

L. G. Hulman

U.S. Nuclear Regulatory Commission

Office of Nuclear Reactor

Regulation

Washington, DC 20555

W. E. Kreger

U.S. Nuclear Regulatory

Commission

Office of Nuclear Reactor Regulation

Washington, DC 20555

0. D. T. Lynch, Jr.

U.S. Nuclear Regulatory Commission

Office of Nuclear Reactor Regulation

Washington, DC 20555

J. L. Mackin

U.S. Nuclear Regulatory Commission

Office of Standards

Development

Washington, DC 20555

E. Markee

U.S. Nuclear Regulatory Commission

Office of Nuclear Reactor Regulation Washington, DC 20555
No. of

Copies

J. Martin

U.S. Nuclear Regulatory Commission

Office of Nuclear Reactor

Regulation

Washington, DC 20555

J. A. Murphy

U.S. Nuclear Regulatory Commission

Office of Nuclear Regulatory Research

Washington, DC 20555

K. G. Murphy

U.S. Nuclear Regulatory Commission

Office of Nuclear Regulatory Research

Washington, DC 20555

T. D. Murphy

U.S. Nuclear Regulatory Commission

Office of Nuclear Reactor Regulation

Washington, DC 20555

L. Soffer

U.S. Nuclear Regulatory Commission

Office of Nuclear Reactor

Regulation

Washington, DC 20555

R. L. Waterfield

U.S. Nuclear Regulatory Commission

Office of Nuclear Reactor

Regulations

Washington, DC 20555

\section{ONSITE}

1 DOE Richland 0perations Office

H. Ransom 
51 Pacific Northwest Laboratory

W. J. Bair

R. L. Drake

G. R. Hoenes

W. E. Kennedy

H. V. Larson

R. B. McPherson

B. A. Napier

W. F. Sandusky

J. K. Soldat

31 D. L. Strenge

R. C. Thompson

C. M. Unruh

E. C. Watson

L. D. Williams

5 Technical Information Files

2 Publishing Coordination 

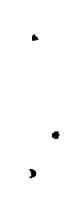

. 